\title{
Weighing regional scrap availability in global pathways for steel production processes
}

\author{
Maria Xylia 1 - Semida Silveira • Jan Duerinck • \\ Frank Meinke-Hubeny
}

Received: 31 March 2017 / Accepted: 25 October 2017 /Published online: 25 November 2017

(C) The Author(s) 2017. This article is an open access publication

\begin{abstract}
This study analyses the impact of the rising availability of steel scrap on the future steel production up to the year 2100 and implications for steel production capacity planning. Steel production processes are energy, resource, and emission intensive, but there are significant variations due to different production routes, product mixes, and processes. This analysis is based on the development of steel demand, using the Steel Optimization Model, which provides a region-detailed representation of technologies, energy and material flows, and trade activities. It is linked to the Scrap Availability Assessment Model which estimates the theoretical steel scrap availability. Aggregated crude steel production is estimated to evolve into an almost balanced split by 2050 between the primary production route using iron ore in the blast oven furnace and the secondary route using mostly steel scrap in the electric arc furnace. By 2060, the share of secondary steel production will exceed the share of primary steel production globally. The results also estimate a global increase in scrap use from 611 Mtonnes in 2015 to 1500 Mtonnes in 2050 , with the highest growth being for postconsumer scrap. In 2050 , almost $50 \%$ of post-
\end{abstract}

M. Xylia $(\bowtie) \cdot$ S. Silveira

Energy and Climate Studies Unit, Department of Energy

Technology, School of Industrial Engineering and Management, KTH Royal Institute of Technology, Stockholm, Sweden e-mail: maria.xylia@energy.kth.se

J. Duerinck $\cdot$ F. Meinke-Hubeny

VITO - Flemish Institute for Technological Research, Mol, Belgium consumer scrap is expected to be traded, with the main exporter being China and major importing regions being Africa, India, and other developing Asian countries. The results provide valuable insights on scrap availability and capacity development at the regional level for producers contemplating new investments. Regional availability, quality, and trade patterns of scrap will influence production route choices, possibly in favor of secondary routes. Also, policy instruments such as carbon taxation may affect investment choices and favor more energyefficient and less carbon-intensive emerging technologies.

Keywords Steel production - Steel scrap - Material flow analysis $\cdot$ Energy efficiency $\cdot$ Energy modeling

\section{Introduction}

Iron and steel production processes are energy intensive and responsible for significant amounts of greenhouse gas emissions. From 2002 to 2012, the volume of steel production has increased $72 \%$ globally, and emissions have increased by $75 \%$, representing approximately $25 \%$ of the global industrial emissions (Serrenho et al. 2016). There are, however, large variations in emissions depending on the production route, product portfolios, and carbon intensity of the fuel mix. Many efforts are being made to reduce energy intensity and emissions in the steel sector. In fact, these efforts have resulted in a $50 \%$ decrease in specific energy consumption in iron 
and steel production in the last 30 years (World Steel Association 2012a).

Increasing steel scrap recycling has contributed to reduced emissions, particularly because the route using recycled steel (secondary production route) requires $56 \%$ less energy than the route using iron ore in the primary steel production (Institute of Scrap Recycling Industries 2012). More specifically, the production of 1 tonne of secondary steel requires $9-12.5 \mathrm{GJ} /$ tonne, while 28-31 GJ/tonne are required through a blast oxygen furnace (BOF-primary) route (Yellishetty et al. 2011). Scrap recycling is facilitated by the physical properties of steel as a material, since it can be almost indefinitely recycled without losing its properties (EUROFER 2016). Secondary steel production using an electric arc furnace (EAF) has economic and environmental advantages in comparison to the primary steel production route using blast oxygen furnaces, implying lower energy costs and fewer steps along the process chain (Söderholm and Ejdemo 2008).

The primary production route can be used for producing both long and flat steel products. The share of scrap used in this case is usually supplied at plant level, the so-called pre-consumer scrap (high-quality scrapHQ scrap hereafter). The secondary route is mostly used for long products, for which HQ scrap is not required, and thus, post-consumer scrap (low-quality scrap-LQ scrap hereafter) can be used. EAF is also used for the production of special steels (incl. stainless), and there are many EAFs in North America producing flat steel products.

Several studies have previously investigated material flows, steel stocks, and the role of scrap in steel production. Some of these studies focus on modeling specific countries or regions (Kuramochi (2015) for Japan; Serrenho et al. (2016) for the UK; and Wang et al. (2014, 2015), Wubbeke and Heroth 2014, and Xuan and Yue 2016 for China), while others have a multiregion or global perspective (Morfeldt et al. 2012; Oda et al. 2013; Pauliuk et al. 2013a, b; Yellishetty et al. 2011). Other studies investigate current and potential recycling rates that can be achieved to close the production cycle (Graedel et al. 2011a, b; Wang et al. 2007). In addition to such modeling studies, researchers have addressed the issue of energy efficiency improvement by investigating energy management practices (Johansson 2015), discussing indicators that can better capture energy efficiency from technological shifts (Morfeldt and Silveira 2014) and drivers and barriers to diffusion of new technologies (Arens et al. 2016). These studies conclude that there are knowledge gaps that could be a barrier to diffusion of new technologies for improved performance in terms of energy consumption and emissions.

Our study contributes to the knowledge gained from previous studies, by focusing on the dynamics of steel demand and scrap availability at the regional level. With this study, we aim to fill the gap when it comes to studying the impact of cross-regional contrasts regarding the origin of scrap and demand of steel. In addition, the opportunities that new emerging technologies offer to reduce energy use and emissions are explored, as well as the impact of new policy schemes. The results of the study are useful in the discussion of how new steel production routes and material recycling can contribute to improved circularity in the steel industry at regional and global level.

In this paper, future steel production is analyzed at a global scale, with focus on the rising availability of steel scrap, and implications for production capacity planning. A reliable estimation of steel demand in different regions, together with an evaluation of scrap availability, can provide valuable information to support (i) capacity planning for iron and steel and (ii) investment choices in primary or secondary steel production. An increased share of secondary routes in future steel production could play a significant role in the decarbonization of the sector, as well as in the reduction of energy demand and total production costs. This study's novelty in comparison to previous literature can be summarized in the following key evaluation steps: (i) link and iteration of the Scrap Availability Model with the Steel Production Model, (ii) separation of steel scrap in different quality categories (own, HQ, and LQ scrap), and (iii) link of the aforementioned scrap categories to steel production routes.

As new investments are contemplated, it is important to understand how the balance of steel demand and production will evolve regionally and globally and which production routes and technologies will be most attractive. Regional availability of scrap, quality, and trade patterns will influence investments and favor one route over the other. In addition, policy instruments such as carbon taxation may affect investment choices and potentially favor emerging technologies that reduce the energy and emissions intensity of steel production. In this context, we aim at answering the following research questions: 
- How will scrap availability and quality affect investments on steel production regionally?

- How will the balance of steel demand and production develop in different world regions? What investments can be anticipated in the different regions, either in form of retrofitting existing installations or in green field projects?

- What can be the role of climate policy instruments and emerging technologies in future technology choices?

Following the present introduction, the next section of the paper presents the methodologies and modeling approaches, as well as the scenarios used for the analysis. After that, the modeling results are discussed and, finally, the main conclusions from the study are highlighted in the final section.

\section{Methods and modeling scenarios}

To evaluate the development of steel demand in the world, we use a TIMES model-based Steel Optimization Model, which provides a detailed representation of technologies, energy and material flows, and trade activities in 13 different regions. We link it to the Scrap Availability Assessment Model (SAAM) which estimates the theoretical steel scrap available at regional level. The modeling horizon stretches until the year 2100 , with 2050 serving as benchmark for the analysis. The list of regions taken into account for the analysis can be found in the Appendix.

A key input in the analysis is the estimation of future steel demand. One of the methods defined by the World Steel Association for measuring steel demand is the apparent steel use (ASU). The ASU is defined as "deliveries minus net exports of steel industry goods" and increases the accuracy of steel demand estimations by incorporating trading (World Steel Association 2012b).

To estimate regional pathways for steel demand, a range of inputs are used, such as demographic development and economic growth, the latter also affecting scrap availability. The structural equation for steel demand modeling has been inspired by the error-correction mechanism (Engle and Granger 1987). In this formulation, short- and long-run reactions are considered. In the short term, demand fluctuates with GDP, representing the business cycles, and the second term addresses the long-term relationship. The long-term relationship is derived from the assumption that the steel stock on a per capita basis follows an S-shaped curve of per capita income, stabilizing at levels between 12 to 14 ton steel per capita for developed countries (in line with e.g., Pauliuk et al. (2013b)). This stabilization can be explained by the transition of an industrial-based economy to a services-based economy in all developed countries.

In the following sections, we first present the scenarios used for the analysis in the SAAM and the Steel Optimization Model and then proceed with a description of the two models' structure in more detail.

\section{Scenario definition}

There is a variety of factors that could affect future steel demand and scrap availability, such as economic development, labor productivity, new steel production technologies, trade patterns, policies for carbon pricing and taxation, recycling rates, scrap quality, and differentiations in the share of the steel product categories, both at global and regional level. For this study, we chose to develop the modeling scenarios on varying recycling rates and policy instruments that could impact steel production and demand. The rest of the factors mentioned above are not the subject of detailed sensitivity analysis, but are still considered in both models used, and their impact in the subsequent results is analyzed.

Different scenarios were considered at two levels. At the first level, a variation in steel recycling rates in the SAAM, both for aggregated scrap recycling (HQ and LQ scrap) and with variation solely in pre-consumer (HQ) scrap, is assumed. At the second level, a variation in $\mathrm{CO}_{2}$ price in the Steel Optimization Model, either unilaterally in Europe or globally, is assumed. For the sake of simplicity, the scrap availability projections only from the baseline scenario of the SAAM are used as input to the different $\mathrm{CO}_{2}$ price scenarios of the Steel Optimization Model. In any case, both models are flexible enough to allow testing a variety of assumptions in the scenarios assumed.

When defining the scenarios for recycling rates used in the SAAM, the aim was to cover the most important sources of uncertainty, such as potential recycling of LQ scrap and availability of pre-consumer (HQ) scrap. We assume slower recycling rate growth in scenario 1, achieving $80 \%$ by 2050 at average global level and aggregated for all product categories. In scenario 2 , the increase in the recycling rate is faster and higher, reaching $85 \%$ by 2030 at average global level and 
aggregated for all product categories. Both scenarios are in line with assumptions for current recycling rates and projected maximum global recycling rates available in the literature (see Graedel et al. (2011a, b); Morfeldt et al. (2012)). Scenario 3 focuses on the pre-consumer scrap production rates. Technologies for steel production and steel product manufacturing in general are constantly improving. Therefore, the amount of preconsumer scrap from such processes is expected to decrease, thus potentially causing a deficit in readily available HQ scrap. The three scenarios regarding scrap availability are presented in Table 1.

It should be noted that although at a theoretical basis steel scrap can be almost indefinitely recycled without losing its properties, this is hardly the case in reality. Scrap contamination, especially from copper, is a major cause of inefficiencies in the steel recycling supply chain. Scrap contamination is not explicitly taken into account for this study; however, the recycling rate assumed for 2013 is rather conservative at $60 \%$, reaching, at the most optimistic of the three scenarios, an $85 \%$ in 2030 . The end-of-life recovery rate for iron and steel products has been estimated to be in a range between 70 and $90 \%$ (Graedel et al. 2011a, b). Previous studies indicate that there is a need for a coordinated, global effort for avoiding copper contamination of scrap resources by 2030 (Daehn et al. 2017).

These scenarios are used to construct the various scrap availability pathways shown in the "Scrap availability-results from SAAM" section. As mentioned earlier, in order to link the Steel Optimization Model to the SAAM and scrap availability, the results from scenario 2 are used as the baseline for future scrap availability. Based on this, the scenarios tested within the Steel Optimization Model regarding $\mathrm{CO}_{2}$ price levels are constructed as shown in Table 2.

Scrap purification technologies are also taken into account in the scenarios, and the costs for such technologies are included in the scenarios for the EU region. Scenarios with the lower cost for purification have an indication with "pur". For example, T15EUpur is identical to T15EU except for the lower cost for the scrap purification. The scenarios considered for the analysis are also illustrated in Fig. 1.

\section{TIMES-based Steel Optimization Model}

The Steel Optimization Model was developed by VITO (Flemish Institute for Technological Research) and is based on the TIMES modeling framework (Loulou and Labriet 2008). The TIMES modeling framework (www. etsap.org) has been used to set up the steel production model as an interregional model with 13 regions (see Appendix for a list of regions), covering the world. Besides technical parameters, economic parameters such as CAPEX (capital expenditure) and OPEX (operating expenditure) are relevant input variables for the model. TIMES can be described as a linear programming simulation tool that selects the investment options that best fulfill the demand scenario at the lowest cost throughout the modeling horizon (2014-2100). In other words, TIMES optimizes the total discounted costs (CAPEX, OPEX, fuel and material and transport costs) over this modeling time horizon.

All technologies are characterized by specific input and output requirements. Demand for finished flat products and long products and availability of low- and highquality scrap are exogenous in this model. Tradable goods are finished flat steel products, finished long steel products, and high- and low-quality scrap. Transport costs between regions have been assumed to be constant and independent of the distance at $42 €$ per tonne for scrap, $47 €$ for flat steel products, and $65 €$ for long products.

The technological base year structure is summarized in Appendix Tables 9, 10, and 11. The structure for BOF route and EAF route is presented for long steel and flat steel products and for each region. By-products' valorization are introduced to account for the use of blast furnace gas in electricity production and the use of blast furnace scrap for cement production. Existing base year production capacities and age structure are estimated from historical steel production data, based on the fact that production capacities in a given historical year only marginally exceed production figures. Finally, Appendix Table 12 presents the characteristics of emerging technologies which are available from 2020 onwards.

In the Steel Optimization Model, the following (simplified) possibilities for steel production are defined: (i) the blast oxygen furnace (BOF) route, (ii) the electric arc furnace (EAF) route, and (iii) direct reduction (DIR) in regions with excess gas supply. The three routes are capable of producing flat steel and long steel products. EAF is a $100 \%$ scrap-based technology and BOF and DRI start from iron ore; the main difference is being that in BOF, the chemical reduction of iron ore is based on coke whereas in DRI, it is based on natural gas. 
Table 1 Steel scrap availability scenarios (used in the SAAM)

\begin{tabular}{llll}
\hline Scenario & LQ scrap recycling rates $(\%)$ & HQ scrap shares & HQ scrap recycling (\%) \\
\hline SAAM scenario 1 (lower LQ scrap) & $60(2013)$ to 80 in 2050 & Stable & 100 \\
SAAM scenario 2 (baseline) & $60(2013)$ to 85 in 2030 & Stable & 100 \\
SAAM scenario 3 (lower HQ scrap) & $60(2013)$ to 85 in 2030 & $25 \%$ lower by 2030 & 100 \\
\hline
\end{tabular}

The available technologies within the model can be separated into existing production installations (residual capacity), new installations which need to be constructed before they can be used (green field investment), and emerging technologies, which do not currently exist in the market but are considered as market ready at some point in time during the model horizon. Three emerging technologies, which are currently not established in steel production, are considered as market ready by 2020: (i) top gas recycling (TGR) in the blast furnace, (ii) JET BOF technology, and (iii) a scrap purification technology.

With the top gas recycling technology, the required amount of coke, coal, and electricity is reduced compared to the common BOF technology. The technology is assumed to be made available for the market in the year 2020. Based on expert interviews, the parameters established for the model are shown in Table 3.

The JET BOF technology offers the possibility to increase the share of scrap in the basic oxygen furnace. The technology consists of equipment that blows oxygen, lime, and coal from the bottom into the converter and a hot blast lance which blows oxygen and $1300{ }^{\circ} \mathrm{C}$ hot blast into the bath from the top. For the purpose of our model, we assume a steel scrap share of $18 \%$ for the traditional BOF converter and up to $50 \%$ for the BOF with JET technology. In the model, this technology is available for investments from 2020 onwards.

The last emerging technology is a steel scrap purification process. The basic assumption is that impurities within the steel scrap can be removed at a certain cost, and thus, it becomes possible to convert LQ scrap to HQ scrap. As there is no available literature for the cost of such a process, two variants have been assumed. In the standard variant, the cost for purification is relatively high and exceeds international transport costs. This means that exporting LQ scrap is cheaper than scrap purification. In the low variant, scrap purification is cheaper than international transport cost (see Table 4).

For the two defined steel production routes, the most recent available crude steel production data from the World Steel Association were used to establish production capacities for each existing technology in the 13 world regions. Installed capacity has been estimated from historical production figures. The base year used is 2013 in all modeling scenarios. Available data regarding the remaining lifetime of existing installations was also fed into the model. If remaining lifetime data was not available, historic production data from the World Steel Association were used to calculate an approximation of residual capacity in each region, assuming $85 \%$ availability factor and 40 years lifetime for each

Table $2 \mathrm{CO}_{2}$ price scenarios (used in the Steel Optimization Model)

\begin{tabular}{|c|c|c|c|}
\hline Scenario & $\mathrm{CO}_{2}$ price $\mathrm{EU} 30$ & $\mathrm{CO}_{2}$ price world & Description \\
\hline Baseline & $0 €$ & & A baseline scenario in which no $\mathrm{CO}_{2}$ price is applied. \\
\hline T15EU & $\begin{array}{l}\text { 2015: } 10 € \\
2020 \text { onwards: } 15 €\end{array}$ & $0 €$ & $\begin{array}{l}\text { An Emissions Trading Scheme (ETS) is applied in Europe only. } \\
\text { The } \mathrm{CO}_{2} \text { price is } 10 € \text { per tonne of emitted } \mathrm{CO}_{2} \text { in } 2015 \text { and } 15 € \\
\text { from } 2020 \text { onwards. }\end{array}$ \\
\hline T15WO & $\begin{array}{l}\text { 2015: } 10 € \\
2020 \text { onwards: } 15 €\end{array}$ & & $\begin{array}{l}\text { An ETS is applied globally. The } \mathrm{CO}_{2} \text { price is } 10 € \text { per tonne of emitted } \\
\mathrm{CO}_{2} \text { in } 2015 \text { and } 15 € \text { from } 2020 \text { onwards. }\end{array}$ \\
\hline T50EU & $\begin{array}{l}\text { 2015: } 10 € \\
\text { 2050: } 50 €\end{array}$ & $0 €$ & $\begin{array}{l}\text { An ETS is applied in Europe only. The } \mathrm{CO}_{2} \text { price is } 10 € \text { per tonne of } \\
\text { emitted } \mathrm{CO}_{2} \text { in } 2015 \text { and reaches } 50 € \text { in } 2050 .\end{array}$ \\
\hline T50WO+ & $\begin{array}{l}\text { 2015: } 10 € \\
\text { 2050: } 50 €\end{array}$ & & $\begin{array}{l}\text { An ETS is applied globally. The } \mathrm{CO}_{2} \text { price is } 10 € \text { per tonne of } \\
\text { emitted } \mathrm{CO}_{2} \text { in } 2015 \text { and reaches } 50 € \text { in } 2050 .\end{array}$ \\
\hline
\end{tabular}

In all scenarios in the Steel Optimization Model, SAAM scenario 2 results (see Table 4) are used as input for the scrap availability projections 
Fig. 1 Summary of modeling scenarios used in the SAAM and Steel Optimization Model
Scrap availability (SAAM)

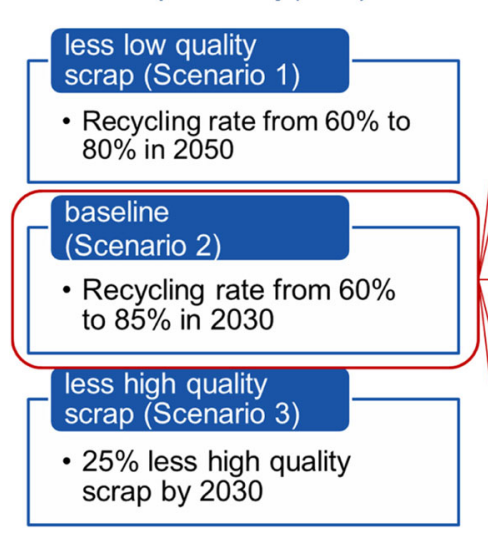

Carbon pricing (Steel Optimization Model)

\section{baseline}

- No carbon price placed $(0 €)$

T15 - EU

- carbon price $15 €$ after 2020

T15 - WORLD

- carbon price $15 €$ after 2020

T50 - EU

- carbon price up to $50 €$ by 2050

T50 - WORLD

- carbon price up to $50 €$ by 2050 installation. The residual capacity capital expenditure is considered sunk costs, meaning these costs are not accounted for in the cost minimization equation of the model. As a result of this exercise, the different regions of the world have very different profiles in terms of residual production capacity. The more recent investments (as for example in the case of China) imply later depreciation of the residual capacity within the region.

For investments in future production capacities, technology parameters with increasing efficiencies are developed along the time line of the modeling horizon. When new production capacities are required, two choices are available according to the model. CAPEX can be spent to retrofit existing installations or be invested in greenfield projects allowing comparable performance. Retrofitting existing plants certainly requires less capital, but is limited to historical built

Table 3 Comparison of input/output commodities for BOF and BOF with top gas recycling

\begin{tabular}{llll}
\hline Commodity & $\begin{array}{l}\text { BOF (GJ/ } \\
\text { tonne steel) }\end{array}$ & $\begin{array}{l}\text { BOF with top gas } \\
\text { recycling } \\
\text { (BOF TGR) }(\mathrm{GJ} / \\
\text { tonne steel) }\end{array}$ & $\begin{array}{l}\text { Comparison } \\
\text { BOF vs. } \\
\text { BOF TGR } \\
(\%)\end{array}$ \\
\hline $\begin{array}{c}\text { Coke gas input } \\
\text { Coal input }\end{array}$ & 9.3 & 5.9 & -37 \\
$\begin{array}{c}\text { Electricity } \\
\text { input }\end{array}$ & 0.5 & 5.2 & -16 \\
$\begin{array}{c}\text { Blast furnace } \\
\text { gas output }\end{array}$ & 3.25 & 0.2 & -60 \\
\hline
\end{tabular}

Source: Parameters derived from consultation with steel production technology experts

Only commodities listed, with variation in input or output per pig iron output (in Mtonne) capacities. Based on expert interviews and the study "Steel's Contribution to a Low-Carbon Europe 2050" (The Boston Consulting Group and Steel Institute VDEh 2013), CAPEX and retrofit parameters were developed, as listed in Table 5, and fed into the model.

In summary, at some point in time in the modeling horizon, a region has an overall production capacity that is an aggregate of residual capacity of what was already established in the base year, some retrofit capacity of existing installations, and new production plants built in the form of greenfield investments where needed. The detailed scrap availability values extracted from the Scrap Availability Assessment Model (SAAM) are fed into the Steel Optimization Tool, improving the accuracy of results and their relevance for the steel sector. The structure of the Steel Optimization Tool is illustrated in Fig. 2.

Scrap availability assessment model

The SAAM was developed in the Energy and Climate Studies Unit at KTH as part of the KIC InnoEnergyfunded project Energy Systems Analysis Agency $\left(\mathrm{ESA}^{2}\right)$. The model calculates the theoretical maximum scrap availability at a specific point in time, for a specific country or region. The total scrap becoming available is divided into scrap that is actually recycled and scrap that remains unexploited. SAAM provides information on the availability of steel scrap and the accumulated steel stock in society, thus filling a gap in the comprehensive mapping of changes in steel stock for the countries included in the World Steel Association database. Steel scrap availability is influenced retrospectively by the steel products' life cycle. For this reason, we collected 
Table 4 Technical parameters of emerging steel scrap purification technology

\begin{tabular}{|c|c|c|}
\hline & $\begin{array}{l}\text { Standard } \\
\text { variant }\end{array}$ & $\begin{array}{l}\text { Low-cost } \\
\text { variant }\end{array}$ \\
\hline CAPEX (€/tonne) & 200 & 100 \\
\hline $\begin{array}{l}\text { VAROM (variable operation } \\
\text { and maintenance cost) (€/tonne) }\end{array}$ & 30 & 15 \\
\hline $\begin{array}{l}\text { FIXOM (fixed operation } \\
\text { and maintenance cost) }(€ / \text { tonne })\end{array}$ & 10 & 5 \\
\hline Efficiency (\%) & 90 & 90 \\
\hline Lifetime (years) & 40 & 40 \\
\hline
\end{tabular}

Source: Consultation with steel production technology experts

historical data for the ASU before proceeding to estimations for scrap availability in the future. Another input needed is the future steel demand projections, and this is where the linkage between the SAAM and the TIMESbased model is created in a recursive manner.

The methodology for the development and application of SAAM is described in more detail in Morfeldt et al. (2015) and Xylia et al. (2014). SAAM was updated from a first global version in the first study to a second version in which country-detail and regional aggregation was included. For the present study, SAAM is updated further to include steel scrap trade and further refined in relation to recycling rates and product lifetime assumptions. The steel stock and scrap availability calculations are also updated with the use of smoothing functions that increase accuracy of the results. The historical data on ASU for finished steel products for 109 countries was gathered from 1967 to 2013 from the World Steel Association (2013). Since no data were available for the period before 1967, an annual growth of $3.5 \%$ was assumed for the previous years, in line with assumptions made, for example, by Grosse (2010).

SAAM calculates the scrap availability for each country, using specific country data for the sector split into the various steel products and their lifetimes (see Pauliuk et al. (2013b). The model divides available scrap into three categories: (i) own scrap (produced within the steel plant from production processes), (ii) new scrap (also known as pre-consumer, or HQ scrap, produced from steel manufacturing processes), and (iii) old scrap (also known as post-consumer, LQ scrap, produced at the end of life of steel products) (Morfeldt et al. 2015). Own and new scraps are considered to be immediately available for recycling. Old scrap becomes available after some time, depending on the lifetime of each steel product category (e.g., appliances, vehicles, construction, and machinery). Own scrap is estimated by SAAM, but it should be noted that this is reported separately from pre-consumer HQ scrap in this study, where needed. SAAM uses a bottom-up approach that combines historical steel consumption figures for

Table 5 CAPEX and retrofit fraction for technology investments

\begin{tabular}{llll}
\hline Technology & CAPEX & Unit & Retrofit fraction \\
\hline Finishing long & 85 & $€ /$ tonne -year & 0.5 \\
Finishing flat & 185 & $€ /$ tonne -year & 0.5 \\
Casting & 80 & $€ /$ tonne -year & 0.5 \\
BOF & 113 & $€ /$ tonne -year & 0.5 \\
EAF & 169 & $€ /$ tonne -year & 0.5 \\
Blast Furnace & 273 & $€ /$ tonne -year & 0.5 \\
Sinter & 56 & $€ /$ tonne -year & 0.3 \\
Coke plant & 399 & $€ / \mathrm{kW}$ & 0.3 \\
DRI & 230 & $€ /$ tonne -year & 0.5 \\
Pellets (DRI) & 62 & $€ /$ tonne -year & 0.3 \\
Blast furnace gas for electricity plant & 1200 & $€ / \mathrm{kW}$ & 1.0 \\
Coal electricity plant & 1800 & $€ / \mathrm{kW}$ & 1.0 \\
STEG gas electricity plant & 960 & $€ / \mathrm{kW}$ & 1.0 \\
Clinker production & 270 & $€ /$ tonne -year & 1.0 \\
\hline
\end{tabular}

Source: Consultation with steel production technology experts. (Coal and STEG electricity plants and clinker production have been added to the model structure to account for the valorisation of by-products in BOF steel production, i.e., electricity from blast furnace gas will have to be produced by another source and blast furnace slags are used as a perfect substitute for clinker in cement production) 
Fig. 2 Structure of the Steel Optimization Tool

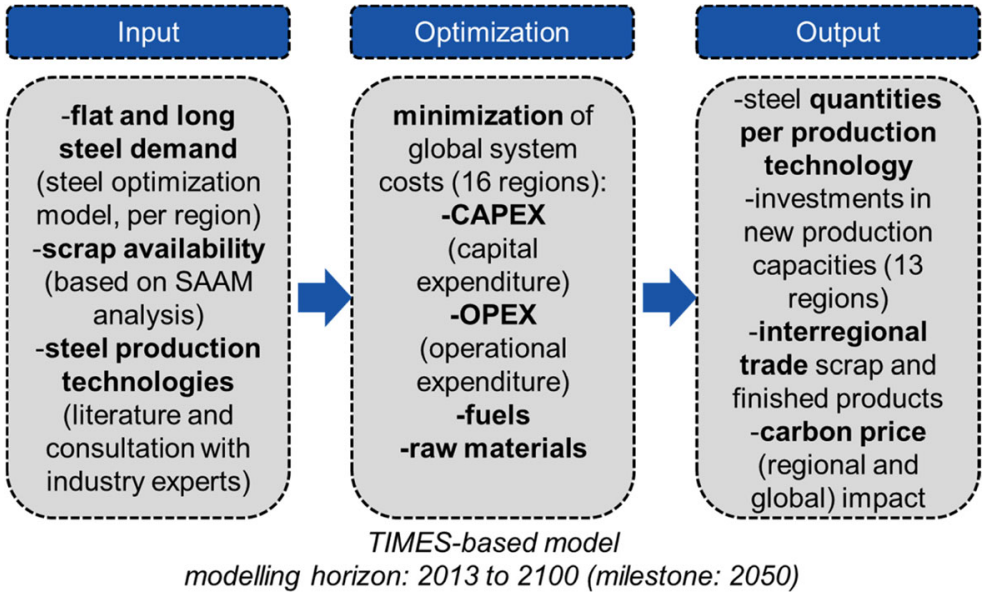

different categories and assumptions on recycling rates based on the available literature (see Graedel et al. (2011a, b), Pauliuk et al. (2013b), and Wang et al. 2007, among others). The structure of the SAAM is illustrated in Fig. 3.

\section{Results and discussion}

Regional steel demand projections

The apparent steel use (ASU) projections are illustrated in Fig. 4. A sharp slowdown is expected for China from 2020 onwards. This decrease is explained by the saturation effect following from increased per capita steel stock and the demographic evolution in China resulting from the one child policy to date. Around 2055, one can observe a second turning point in the ASU projection for China. This one is related to the age structure of the steel stock. The steel stock that is accumulated between 2000 and 2020 comes to the end of its life and has to be replaced. Similar patterns are observed in other regions. Around 2050-2055, the world steel market will be dominated by four regions, namely China, India, other developing Asia (ODA), and Africa, with almost equal shares.

These projections entail some level of uncertainty, which is affected by parameters such as the assumption of steel stock per capita stabilization at 12 tonnes/capita (see Pauliuk et al. (2013b)), the population development (here, the medium fertility scenario of the $\mathrm{UN}$ is used (United Nations 2015a)), assumptions for the labor productivity growth, and the lifetime assumption for steel products. To address these issues of uncertainty, we performed a sensitivity analysis of the ASU values to the parameters discussed above. The results are summarized in Table 6, where it can be seen that the ASU estimations we included are the most sensitive to a decrease in productivity rates. More specifically, when assuming lower average productivity rates between 2010 and 2050, this leads to a decreased yearly growth of ASU, and thus, the ASU will be lower by $31 \%$ by 2050 in comparison to the reference assumptions. Similarly, ASU in 2050 is higher by $22 \%$ if higher fertility rates are assumed. The steel stock capita stabilization rates have a somehow lower impact to the ASU values than the rest of the parameters tested under the sensitivity analysis.

Scrap availability—results from SAAM

The basis for calculating scrap availability is the apparent steel use (ASU). Figure 5 shows the historical scrap availability estimations from SAAM from 1970 to 2013, as well as the future scrap availability estimations until 2100 based on the three scenarios previously defined in the "Methods and modelling scenarios" section.

Scenario 3 shows slightly lower scrap availability due to the lower amount of HQ scrap available in comparison to the other two scenarios. This analysis indicates that the sensitivity of total scrap availability (and consequent scrap use in steel production) is low for the different recycling rates assumed in the respective scenarios. Therefore, in the results presented hereafter in this paper, the focus is on scenario 2 (the baseline scenario for scrap availability). It should be noted that uncertainties related to the estimation of steel demand 
Fig. 3 Structure of the Scrap Availability Assessment Model (SAAM) (Source: Morfeldt et al. 2015)

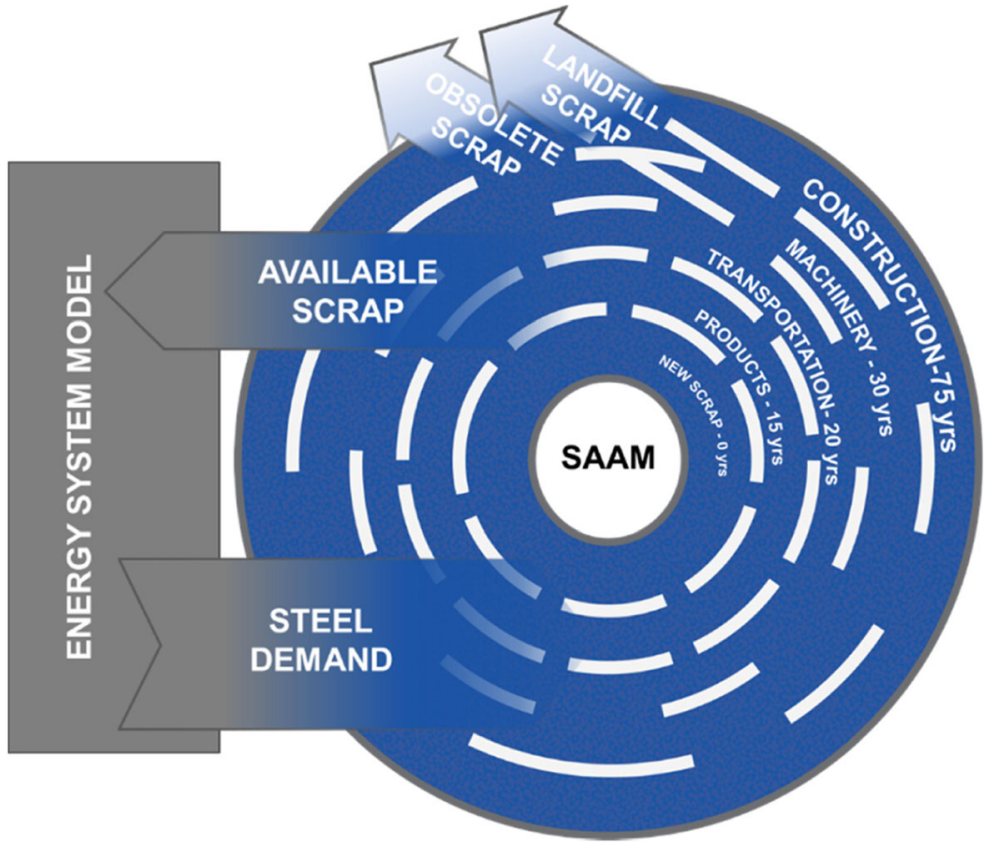

also have impact on the scrap availability estimations since the two parameters are linked.

The transformation of industrial processes that ensures increased efficiency of material utilization entails a variety of side effects, ranging from improved energy efficiency to reduced amount of by-products, such as HQ scrap. Such transformations impact the availability and recyclability of scrap. For example, in 2050, the
Fig. 4 Apparent steel use projections

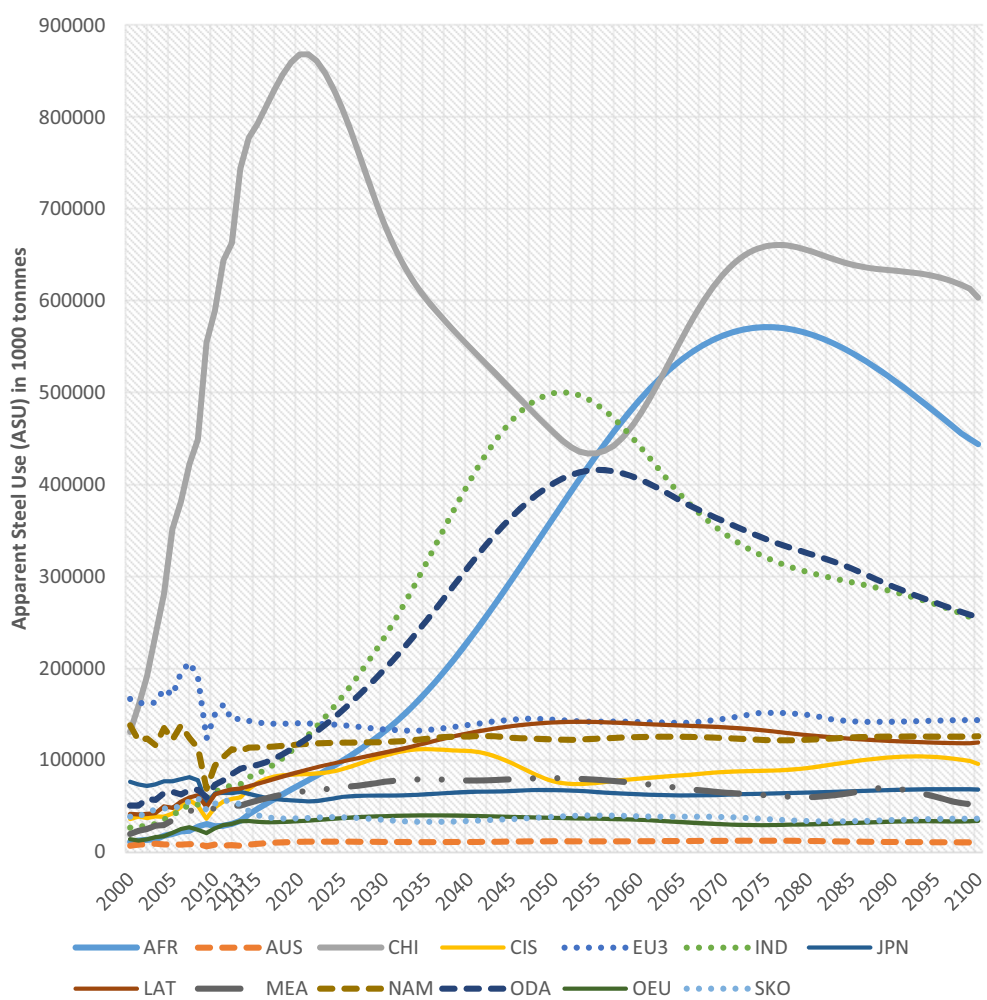


Table 6 Average yearly growth rates for global ASU between 2010 and 2050: sensitivity analysis for selected model parameters and comparison with historical growth rates between 1980 and 2010

\begin{tabular}{|c|c|c|c|c|c|c|}
\hline & \multirow{3}{*}{$\begin{array}{l}1980-2010 \\
\text { Average } \\
\text { historical growth } \\
\text { rates }(\%)\end{array}$} & \multicolumn{5}{|l|}{$2010-2050$} \\
\hline & & \multirow{2}{*}{$\begin{array}{l}\text { Reference } \\
\text { growth } \\
\text { rates }(\%)\end{array}$} & \multicolumn{4}{|c|}{ Sensitivity analysis } \\
\hline & & & $\begin{array}{l}\text { Lower fertility } \\
\text { rates (see UN } \\
\text { scenarios) }(\%)\end{array}$ & $\begin{array}{l}\text { Higher fertility } \\
\text { rates (see UN } \\
\text { scenarios) }(\%)\end{array}$ & $\begin{array}{l}\text { Lower } \\
\text { productivity } \\
\text { rates }(\%)\end{array}$ & $\begin{array}{l}\text { Higher steel stock } \\
\text { stabilization rates (at } \\
13 \text { tonnes/capita) (\%) }\end{array}$ \\
\hline Population & 1.5 & 0.7 & 0.5 & 1.1 & 0.7 & 0.7 \\
\hline GDP & 3.0 & 3.3 & 3.0 & 3.6 & 2.3 & 3.3 \\
\hline Average productivity & 1.5 & 2.6 & 2.5 & 2.5 & 1.6 & 2.6 \\
\hline $\begin{array}{l}\text { Population-weighed } \\
\text { productivity }\end{array}$ & 3.4 & 3.6 & 3.6 & 3.6 & 2.5 & 3.6 \\
\hline ASU & 3.0 & 2.1 & 1.8 & 2.6 & 1.2 & 2.3 \\
\hline $\begin{array}{l}\text { ASU difference by } \\
2050\end{array}$ & & & -10 & 22 & -31 & 6 \\
\hline
\end{tabular}

\footnotetext{
${ }^{1}$ Population-weighed productivity is higher than average productivity because higher productivity increase is assumed for developing countries
}

difference between scenarios 2 and 3 in terms of available HQ scrap is approximately 200 Mtonnes, which is almost as much as the total amount of LQ scrap used in secondary steel production in 2013 (245 Mtonnes, according to the Bureau of International Recycling (2012)). Removing this amount of HQ scrap that can be straightforward used in steel production processes without the risk of contamination from tramp elements (e.g., copper) could make the use of scrap purification technologies for LQ scrap becomes a priority in order to sustain the material flows needed for secondary steel production. As a result, policy instruments to encourage such new technologies would be necessary.

Figure 6 shows the pre-consumer scrap availability, which is estimated to quadruple by 2050 compared to 2013, from 200 Mtonnes to between 731 (scenario 1) and 831 Mtonnes (scenarios 2 and 3). Figure 6 also shows the sharp decrease of new (HQ) scrap availability when steel production efficiency improves so as to reduce new scrap. This estimation for LQ scrap availability is in line with previous estimations that showed a global LQ scrap availability of ca. 760 Mtonnes by 2050 (Oda et al. 2013). Figure 7 shows a sharp increase of available LQ scrap after 2020.

Looking into post-consumer scrap availability per region, Fig. 8 shows indicatively the results of scenario 2. Here, China experiences a rapid increase of LQ scrap availability by 2020 , reaching a first peak by 2050 . The EU region is leading in LQ scrap availability before China takes over but, as the steel stock from China, Africa, India, and ODA gradually increases due to faster development, the amount of available LQ scrap also
Fig. 5 Scrap availability (Mtonne) 1970-2100

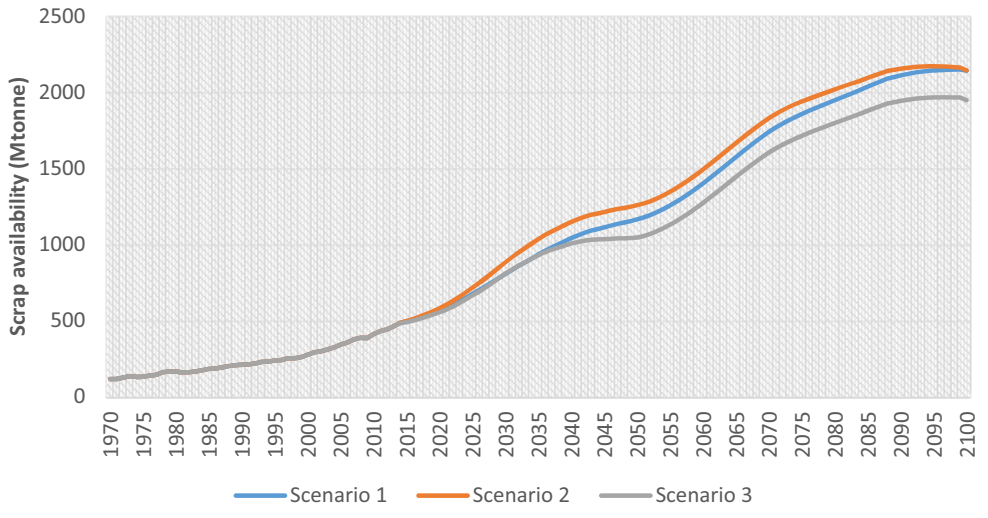


increases. Therefore, EU available LQ scrap will be of less importance after 2020, compared to the aforementioned regions. Previous studies have estimated LQ scrap availability in China to reach ca. 400 Mtonnes by 2050 (Wang et al. 2014; Xuan and Yue 2016). Our projections are within the same range, albeit somewhat lower at ca. 350 Mtonnes.

It should be pointed out that SAAM calculates the theoretical amount of scrap becoming available in a year, based on global estimations of recycling rates from the literature, and national product categories split, as explained previously. It is, therefore, not certain that all scrap becoming available under these theoretical conditions will actually be recycled, but it can be assumed that in most cases, it will be so, as scrap is a valuable commodity. The validation of the model, based on historical values from the Bureau of International Recycling (BIR), show that SAAM calculates global scrap availability values that are quite close to the historical values. As mentioned earlier, according to BIR (Bureau of International Recycling 2012), the amount of scrap actually recycled in 2013 was 245 Mtonnes. SAAM calculates the post-consumer scrap availability in 2013 to be 225 Mtonnes, which is a difference of $8 \%$. If one adds scrap that has perhaps been traded and not recorded properly in international trade databases such as COMTRADE (United Nations 2015b), or scrap used by foundries not being taken into account, then SAAM's results are very close to reality when it comes to estimations at global level.

At regional level, there are more uncertainties when calculating scrap availability, due to the insufficient trade information and the existence of indirect steel trade (embedded steel in products produced in one region and sold to other regions) (World Steel Association 2012b). Such is the case for China, where SAAM calculates scrap availability $30 \%$ higher on average compared to actual BIR values for 2010-2013. On the other hand, SAAM calculates $50 \%$ less scrap availability compared to the actual scrap recycled in the EU according to BIR in the period from 2010 to 2013. This clearly illustrates the problem with indirect steel trade, as apparently a high Chinese ASU leads to large amount of products sold to the high-income EU region, which then utilizes the scrap at the end of the product lifetime. Including indirect steel trade in SAAM would be highly beneficial for increased result accuracy at regional level, and this can be done in the future. The problem when accounting ASU and the impact of indirect steel trade is also confirmed for the case of the UK, as per documented in Serrenho et al. (2016).

Furthermore, indirect steel trade has also significant impact on the steel demand estimates at the regional level. There is lack of comprehensive indirect steel accounting data and methodologies which should be addressed in future research, in order to improve the accuracy of ASU and scrap estimations, as well as provide new insights to trade patterns and interregional material flows.

World steel production-results from the Steel Optimization Model

Figure 9 shows a steady increase in global steel production, reaching approximately 2.7 Gtonnes of combined long and flat steel production in 2050, and peaking around the year 2070 at approximately 2.8 Gtonnes. The split between global EAF production and BOF production is estimated to evolve from a 1:2.5 relation in 2015 (an estimated 1.16 Gtonnes via BOF versus 0.46 Gtonnes via EAF) towards an almost balanced production split in 2050 (ca. 1.5 Gtonnes via BOF versus 1.2 Gtonnes via EAF). In 2060, the share in EAF will exceed the production in BOF globally.

One can also notice in Fig. 10 the domination of China when it comes to installed capacity of BOF up to 2050 , as resulting from the simulations. In the years from 2050 to 2100, a share of the Chinese BOF capacity is lost, and its place is taken by the gradual increase of EAF shares. Additionally, the figure shows the increase of installed capacity for both BOF and EAF for Africa, which rises after 2030 to reach significant shares of the total global installed capacity for both BOF and EAF. It should be noted that when comparing Figs. 9 and 10, steel production values are always lower than installed capacity. In the model, this is represented by an average utilization factor which is constrained to an upper limit of $85 \%$, which can be even lower in cases where regional steel demand is decreasing.

Analyzing the global flat and long steel production separately, we found that demand for both product groups will steadily increase and experience, with the model showing a peak production of 1.6 Gtonnes for flat products and 1.2 Gtonnes for long products in 2070 . The results regarding the evolution of the production routes for both product groups are different. While the EAF share increases from $38 \%$ in 2015 to $70 \%$ in 2050 for long steel, the flat steel production balance remains 
Fig. 6 Pre-consumer scrap (new or HQ scrap) (Mtonne) 19702100

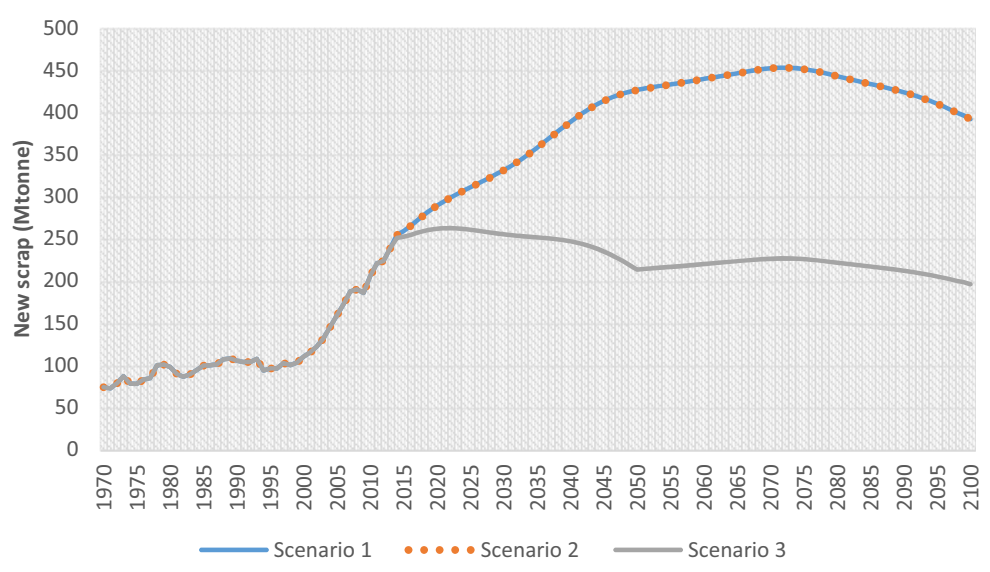

almost constant, with an EAF route production of 17\% in 2015 and $19 \%$ in 2050 . This evolution is confirmed by observing that the majority of the investments for the flat steel production are flowing towards new BOF installations, while for long steel, new investments are mostly related to new EAF installation that capitalize on the increasing availability of scrap (see Figs. 11 and 12). In contrast to the global steel production outlook, region-specific projections for the EU 30 show only a moderate growth of $23 \%$ for flat steel production (an estimated 86 Mtonnes in 2015 and 106 Mtonnes in 2050), and stable production for long products until 2050 (an estimated 54 Mtonnes in 2015 and 53 Mtonnes in 2050).

Analyzing the model output for flat steel production in Europe in greater detail, we observe in the model results that the European demand is strong and stable enough to trigger capital investments in BOF installations within Europe for each observed time period until 2100. Only a small amount of flat steel demand in 2070 , 2080, and 2100 is met by imports from other world regions. In the year $2050,88 \%$ of flat steel production will originate from new BOF installations and approximately $12 \%$ from new EAF installations, using HQ scrap. In Europe, long products will purely originate from the EAF route. New investments in BOF installations are not observed, which is the result of the readily available LQ scrap as raw material input. Similar to the flat steel analysis, it can also be observed that the European demand for long steel is met in the model by European production only. While Europe continues to lose market share in the aggregated crude steel production, as the global growth outpaces the EU 30 growth, one can observe that the steel production industry in

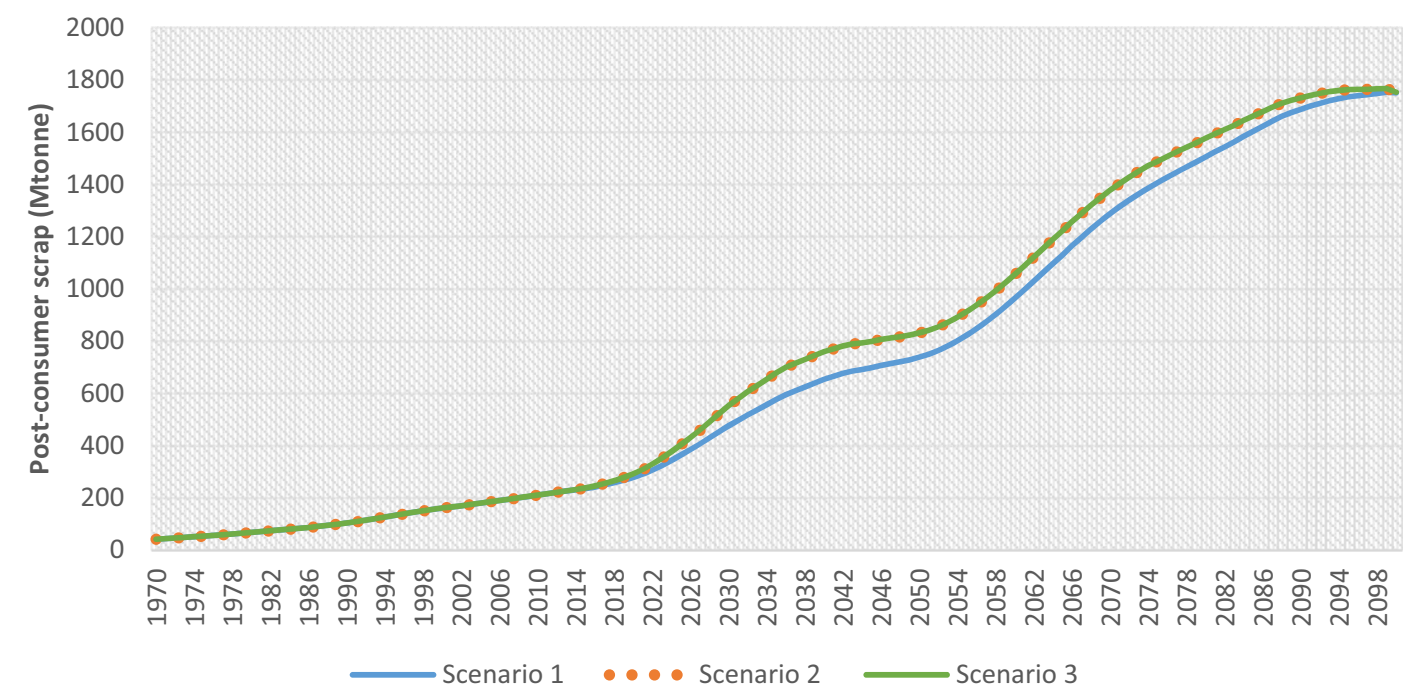

Fig. 7 Post-consumer (LQ) scrap 1970-2100 (Mtonne) 


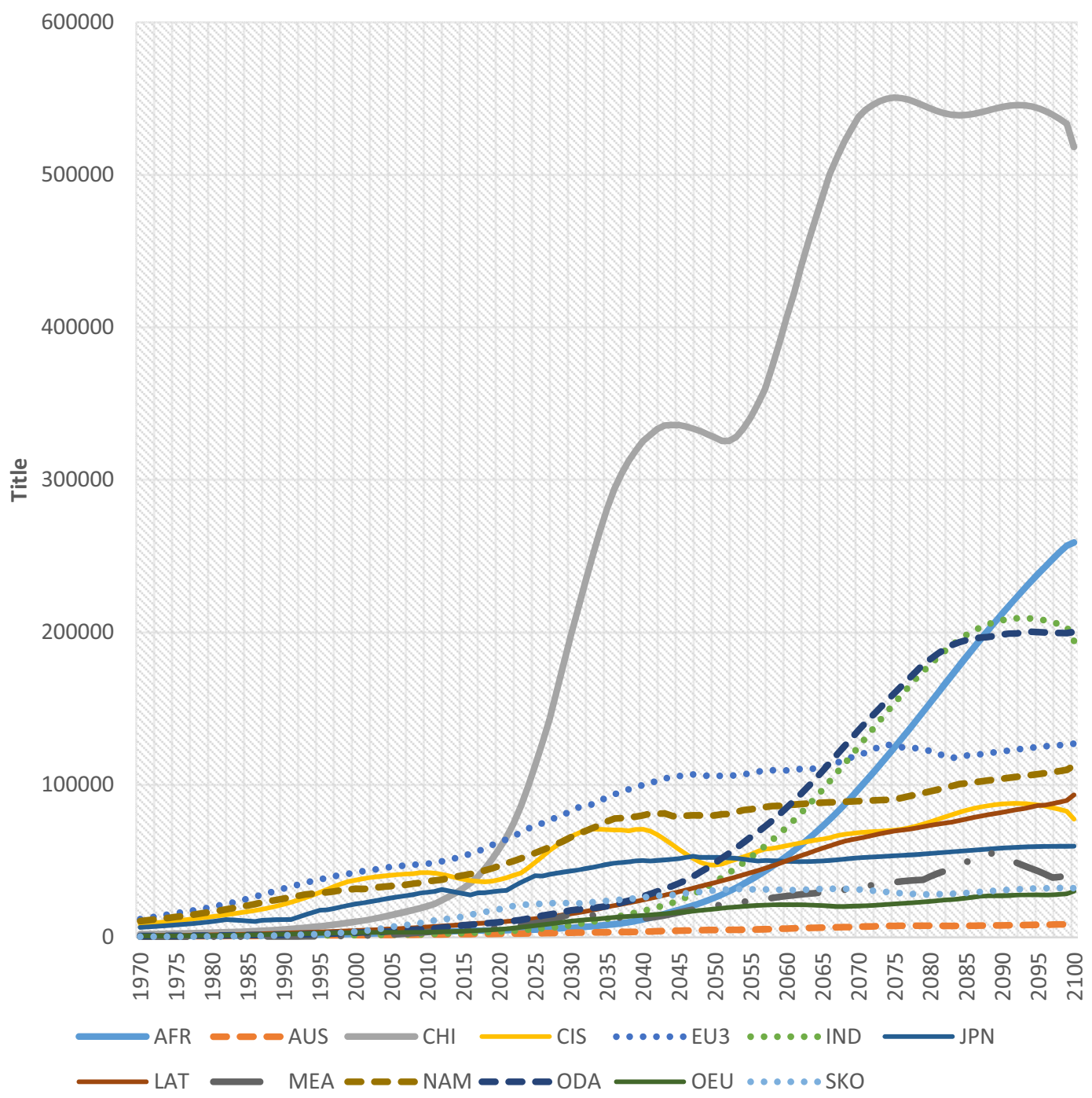

Fig. 8 Post-consumer (LQ) scrap availability per region, scenario 2, 1970-2100 (Mtonne)

Fig. 9 World steel production by technology (baseline scenario)

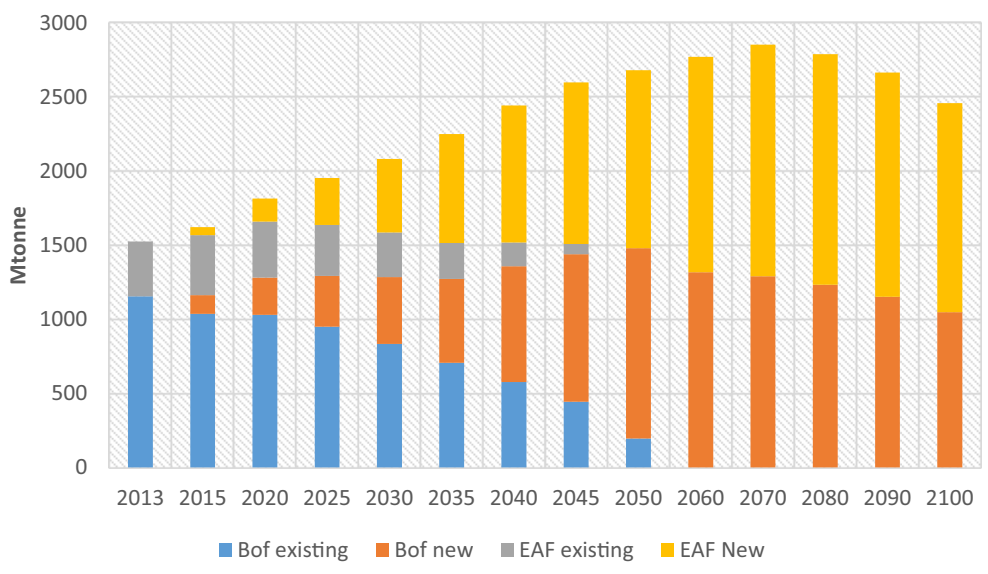




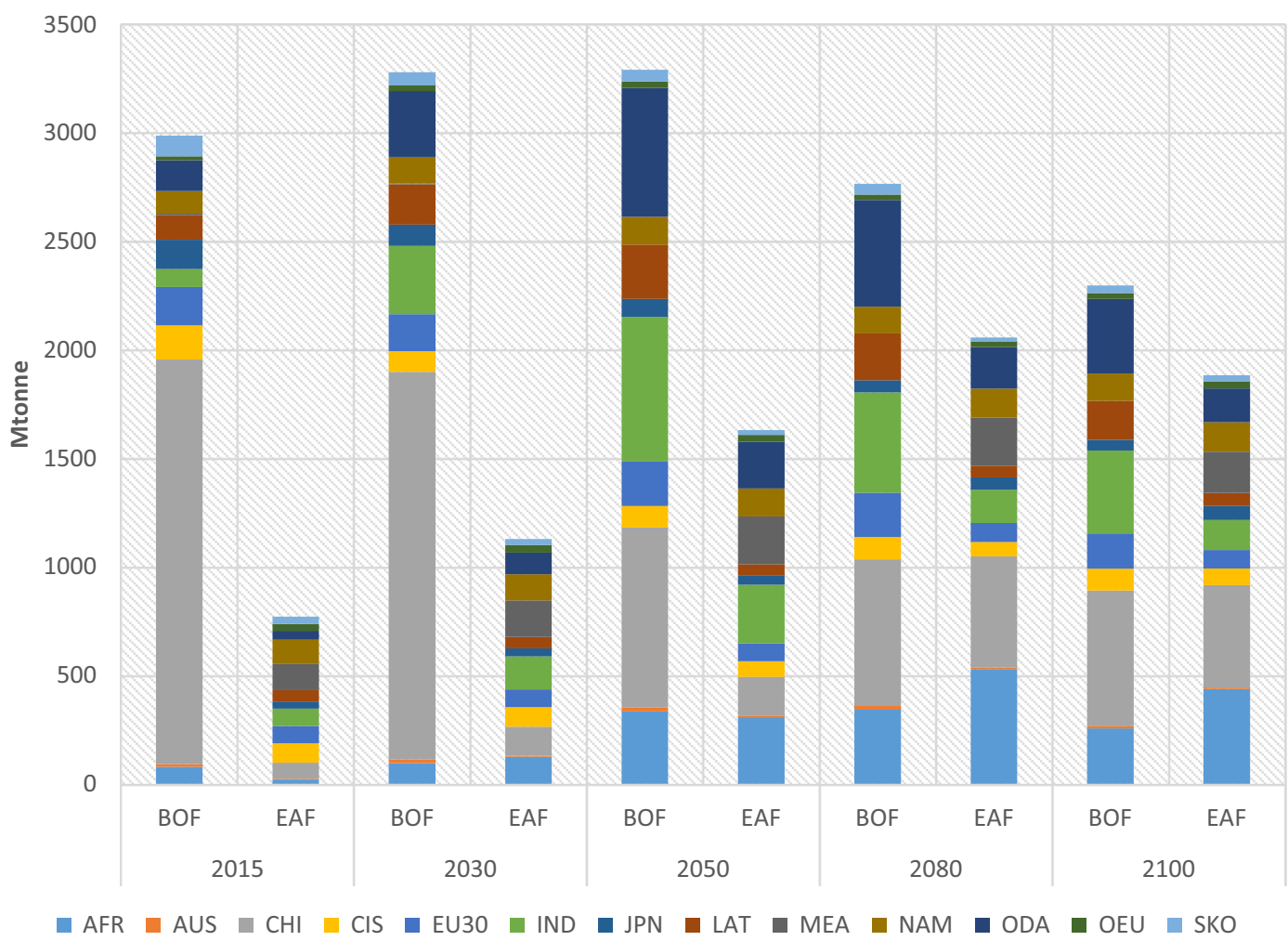

Fig. 10 Installed BOF and EAF capacity per region 2015-2100

Europe remains vital in long and flat steel production in the model.

It should be noted that a higher resolution in the various product categories is not taken into account for estimating the steel demand split into long and flat products. Such higher resolution is only taken into account when estimating the scrap availability and product

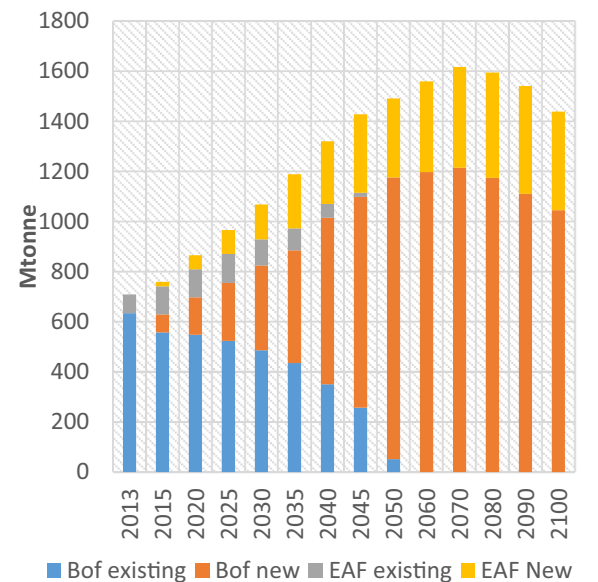

Fig. 11 World flat steel production by technology (baseline scenario) lifetimes. This split is defined based on analyzing the historical split values from the available data sources (the World Steel Association data) and then applying a regression for extrapolating to the projected future values. Including a higher resolution separating long and flat steel products into different product categories would increase the accuracy of the results. Such an

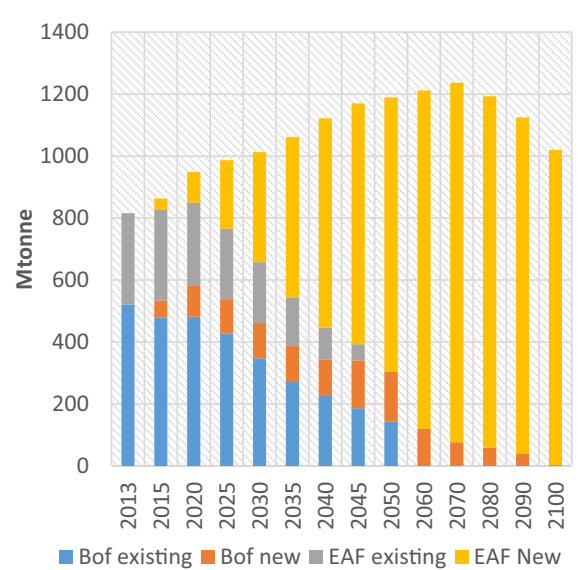

Fig. 12 World long steel production by technology (baseline scenario) 
update is possible; however, the lack of available, conclusive data on such a split is currently a barrier.

\section{Scrap use}

A major focus of this study is the role of steel scrap in future steel production both in Europe and globally. Figure 13 shows the development of the steel scrap use separated by scrap categories for the baseline scenario. Globally, the use of steel scrap is estimated to grow from 611 Mtonnes in 2015 to 1.5 Gtonnes in 2050, a $245 \%$ increase. The three scrap categories are shown in the model to grow from $259 / 238 / 113$ to $426 / 906 /$ 188 Mtonnes of usage for HQ/LQ/own scrap, respectively. The highest growth rate can be observed for the LQ scrap category, which increases by $380 \%$ from 2015 to 2050 . In the base scenario, the aggregated scrap usage is estimated to peak in 2070 close to 1.9 Gtonnes. Comparing the Steel Optimization Model results to the results from SAAM shown in Fig. 7, the LQ scrap availability in SAAM is slightly lower but, if trade and overthe-year transposition of scrap is taken into account, the results converge.

\section{LQ scrap trade}

The large amount of LQ scrap available in the market triggers an increasing trade activity between the world regions. As Fig. 14 depicts, total global imports of LQ scrap in the model increase tenfold from 40 Mtonnes in 2015 to 432 Mtonnes in 2050. This means close to half of the estimated LQ scrap used will be traded among world regions in 2050 (432 Mtonnes traded of 906 Mtonnes used). The majority of the scrap is imported to Africa, India, and ODA. This seems quite reasonable, as most economic development until 2050 is projected to occur in these regions, including a high demand for new infrastructure. Such development requires large amounts of long steel. The largest exporter is by far China with an estimated 275 Mtonnes in 2050, which is equal to $63 \%$ of the global LQ scrap exports (see Fig. 15).

\section{HQ scrap trade}

The overview for HQ scrap is quite different from what was shown previously for LQ scrap. In 2015, the trade is estimated at approximately 40 Mtonnes. The development of trade activity is quite volatile, declining to an estimated 5 Mtonnes in 2050 (see Figs. 16 and 17).

While the group of importing countries is diverse, with India and North America holding the largest share in the projection, the exports are coming from China only. This can be explained by the large (over) capacity in flat steel production that has been installed in the country in recent years. The model chooses to use the BOF installations capacity over the expected lifetime (40 years) because it is economically the most attractive. This results in large amounts of HQ scrap being traded globally from China as production capacity declines.

\section{Impact of recycling rates and $\mathrm{CO} 2$ price}

The use of scrap appears to be determined by the recycling rates, as well as by $\mathrm{CO}_{2}$ price. Globally, there are two relevant periods (see Fig. 18). Up to 2070, all available scrap is effectively recycled into new steel, but from 2070 onwards, excess LQ scrap is only recycled in the low cost variant and when a $\mathrm{CO}_{2}$ price justifies it.

We consider the $\mathrm{CO}_{2}$ price as cost incurred per tonne of emitted $\mathrm{CO}_{2}$ from the production of steel. Reviewing the results of the global $\mathrm{CO}_{2}$ price scenarios, imposing a price does not affect scrap use until 2050. From 2070 onwards, when global steel production peaks, there is an excess of LQ scrap globally. Figure 18 shows that this global excess of LQ scrap cannot be absorbed by the market, even if emerging countries accept to rely almost entirely on scrap import. Introducing a global $\mathrm{CO}_{2}$ price of $15 €(\mathrm{~T} 15 \mathrm{WO})$ or $50 €$ (T50WO) does increase the use of scrap from 2070 onwards. Interestingly, the effect of combining a $15 €$ price scheme with new scrap purification technology (T15WO-scrap upgrade scenario as shown in Fig. 18) has an almost equal effect as a 50 $€$ global $\mathrm{CO}_{2}$ price (T50WO scenario as shown in Fig. 18).

Uptake of new technologies

\section{Top gas recycling}

The top gas recycling technology finds a widespread geographical acceptance in the model, even without the introduction of an emission trading scheme as simulated in the baseline scenario. After a slow uptake in its usage, the technology sees an intense growth period for 10 years from an estimated 39 ktonnes in 2035 to 207 ktonnes crude steel production in 2045 (see Fig. 19). 
Fig. 13 Global scrap use by type: own, LQ, and HQ (base scenario)

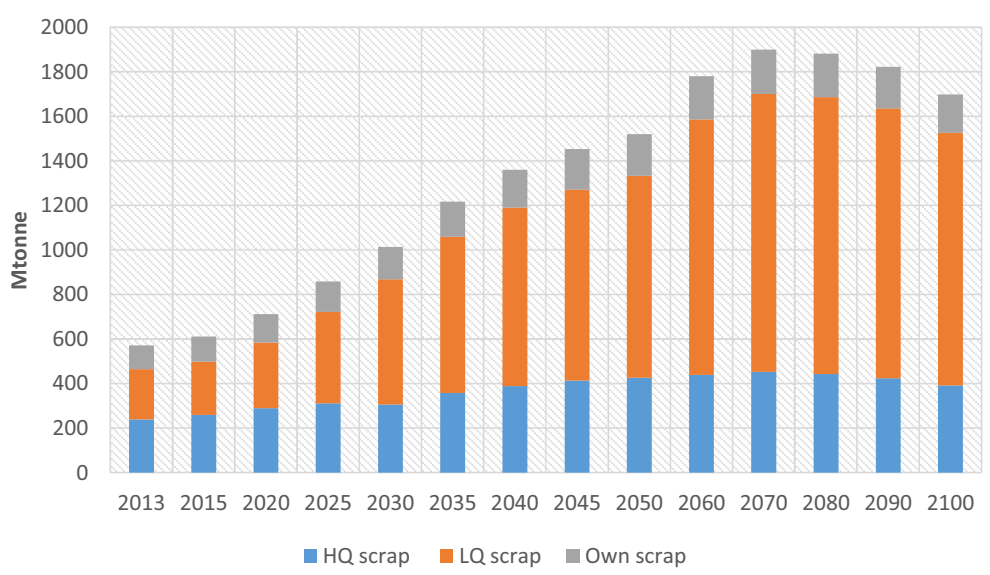

Most applications are installed in India and ODA (other developing Asian) countries, which are the regions with the highest green field investments in BOF production routes.

Since top gas recycling offers significant reduction potential for the input materials coke gas and coal and also electricity, the cost for $\mathrm{CO}_{2}$ emissions has a noticeable impact on the uptake of such technology. Under the T15WO and T50WO scenario, the uptake is faster, meaning it occurs earlier in the model horizon, and higher in absolute numbers. By 2050, the amount of steel produced with such a technology increases under the T15WO scenario in the model from 213 to 285 ktonnes (33\% increase) and under the T50WO scenario up to 563 ktonnes (a $264 \%$ increase in uptake) (see Fig. 20).

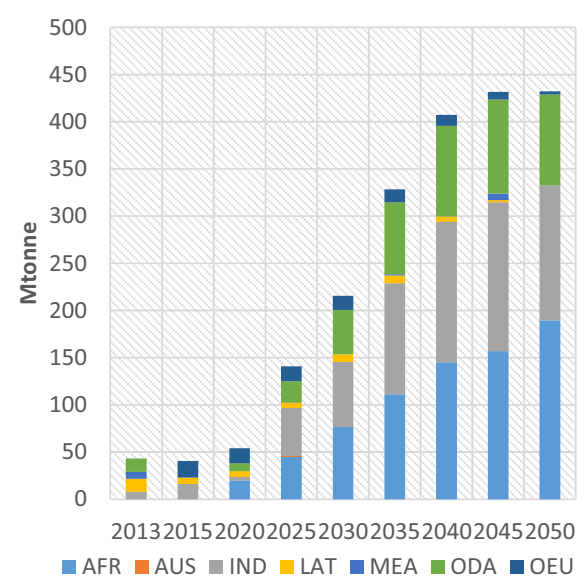

Fig. 14 LQ scrap imports per country (baseline scenario)

\section{JET BOF}

With the JET BOF technology, the scrap share can increase up to a $50 \%$ share in the BOF process. A first observation is that the uptake of this technology is not as significant. In the baseline scenario, JET BOF is not selected at all. This can be explained by the fact that, when excess blast furnace capacity exists or scrap is available, replacing BOF by JET BOF is an attractive alternative for scrap utilization. Once excess blast furnace capacity disappears, JET BOF becomes less attractive. While the dissemination is limited in the T15WO scenario, its global usage increases rapidly under the T50WO scenario (see Figs. 21 and 22). The utilization under the $T 50 W O$ is six times higher, estimated at 600 ktonnes of production.

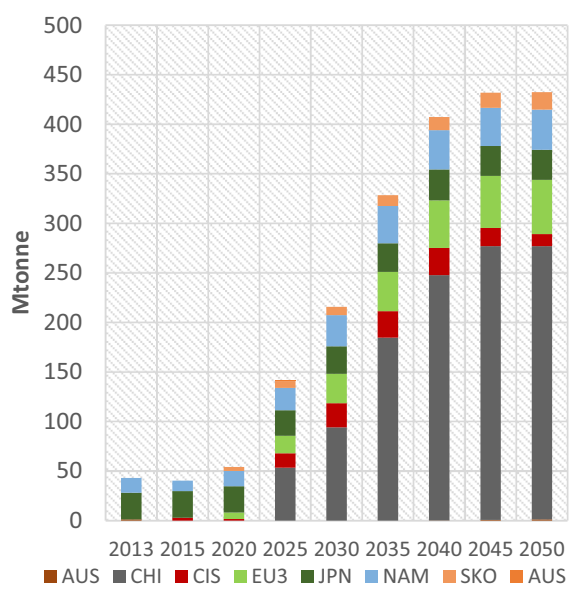

Fig. 15 LQ scrap exports per country (baseline scenario) 


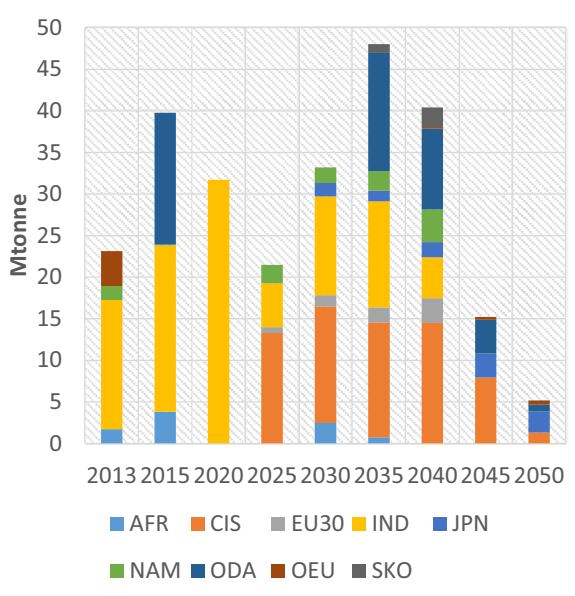

Fig. 16 HQ scrap imports per country (baseline scenario)

\section{Scrap purification}

The results show that scrap purification, meaning a technology converting LQ scrap to HQ scrap, becomes relevant in a situation with global excess LQ scrap. In our model, we do not consider any trade limitations, and thus, local excess scrap easily finds a use elsewhere. The only limiting factor is transport cost. In the "purification" scenarios, the cost of purification has been set at a level below transport cost. Under these circumstances, it might become attractive to invest earlier in this technology, particularly when HQ scrap becomes scarce, such as in scenario 3 for reduced HQ scrap availability and/or when a local $\mathrm{CO}_{2}$ price is applied. In Fig. 23, this is illustrated for two scenarios in which we estimated that 3.5 to 7 Mtonne scrap is upgraded in EU 30. These results are to be considered as pure illustrative as the attractiveness of scrap purification completely depends on the cost.

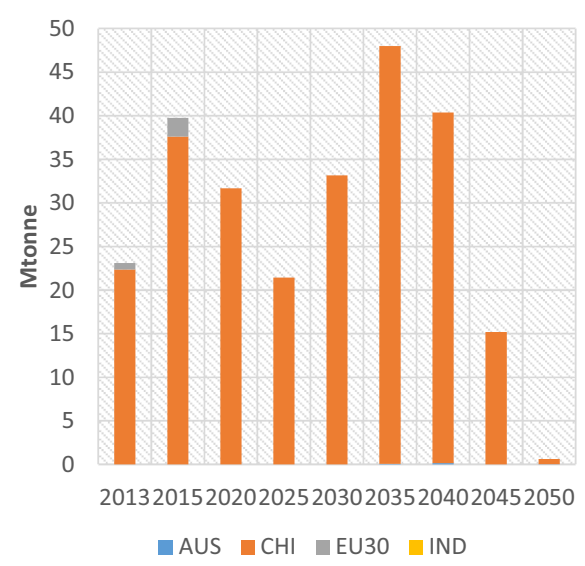

Fig. 17 HQ scrap exports per country (baseline scenario)
$\mathrm{CO}_{2}$ emissions

Figures 24 and 25 give worldwide steel productionrelated $\mathrm{CO}_{2}$ emissions and the evolution of the specific emissions, respectively. The increase in the use of scrap as base material is the main reason for the sharp decrease of the specific emissions, but top gas recycling and JET BOF will contribute as well to the decrease of emissions. In 2050, specific $\mathrm{CO}_{2}$ emissions are expected to be $27 \%$ lower compared to 2013 . An emission reduction of $70 \%$ could be achieved by 2100 .

A unilateral $\mathrm{CO}_{2}$ price introduction in Europe at the level of 15 or $50 €$ will have significant impact on production levels. While the T15EU scenario would result in a stable flat production in Europe from 2020 until 2050 (instead of a 15\% growth in the base scenario), the $50 €$ unilateral EU price (T50EU) would lead to a significant reduction in production levels, resulting in the model in only 68 Mtonnes in 2020, further declining to 22 Mtonnes in 2050 (see Fig. 26). By 2050, this implies only $21 \%$ of the production level in the T50EU scenario compared to the baseline scenario. This information is of particular interest to EU policy makers.

To conclude, our analysis shows that the increasing availability of scrap can foster a transition to the secondary production route (i.e., the EAF) which can possibly surpass the primary production route after 2050 . This, in turn, would imply significant decrease in specific energy and emissions from the steel industry. Energy efficiency and emission reduction improvements should be expected even without the introduction of stricter policy regulations in the future. However, instruments such as a global carbon price might provide additional incentives for a shift towards the secondary route and could potentially create new scrap trading pathways at cross-regional level. In relation to this, the model also shows that the focus of scrap trading flows will shift from Europe to the developing world, as increased economic development leads to an accumulation of steel stock that will eventually become available as scrap in the coming years.

\section{Conclusions}

The combination of the Steel Optimization and the Scrap Availability Assessment Model for analyzing the future of steel production globally provides interesting results from several perspectives. Based on 
Fig. 18 Sensitivity of scrap use to $\mathrm{CO}_{2}$ price and cost of upgrading

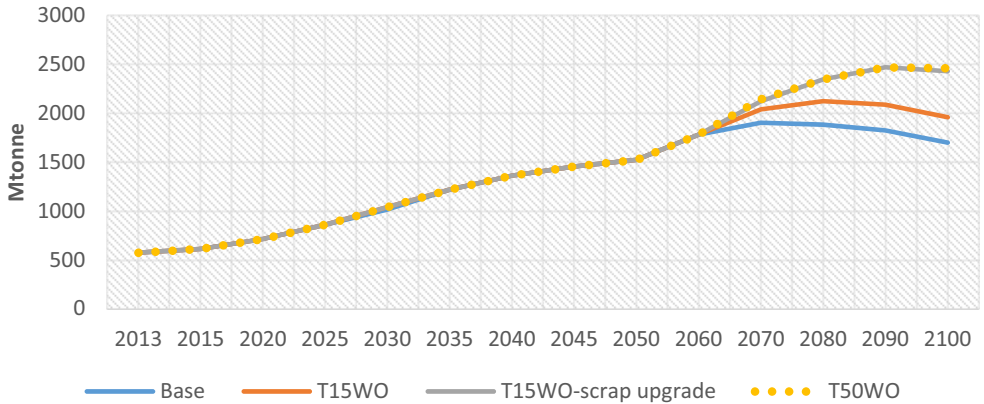

geographically disaggregated estimates of steel demand and scrap availability, the model output improves understanding about the role that secondary routes may play in future steel production, and how different policy options may impact the location of production.

For the global primary and secondary steel production, a steady increase in production can be observed in the model results. The split between global EAF production and BOF production is estimated to evolve from a 1:2.5 relation in 2015 towards an almost balanced production split in 2050 . In 2060 , the production in EAF may potentially exceed the production in BOF globally.

As for the evolution of the production routes for long and flat product groups, the analysis shows that the majority of the investments on flat steel production are flowing towards new BOF installations. Meanwhile, for long steel, the investments are mostly going to new EAF installations to capitalize on the growing amount of available scrap. The EAF share in long steel production is estimated to almost double in 2050, while the flat steel production balance is estimated to remain almost constant with an EAF route production of 17\% in 2015 and $19 \%$ in 2050.

For the EU, the study projects only a moderate growth of flat steel production and stable production levels for long products until 2050. The model results indicate that European demand for flat steel could trigger capital investments in BOF installations within Europe for each observed time period until 2100. However, the model is not currently considering other options that could enhance the potential for flat steel production from post-consumer scrap, i.e., technologies for scrap contaminant separation. Another factor that should be taken into account is the risks entailed by steel overcapacity which can be observed even at international level.

The model results indicate that by 2050 , a large share of long products will originate from the EAF route, which is the result of the readily available LQ scrap in Europe. It is important to avoid carbon leakage as

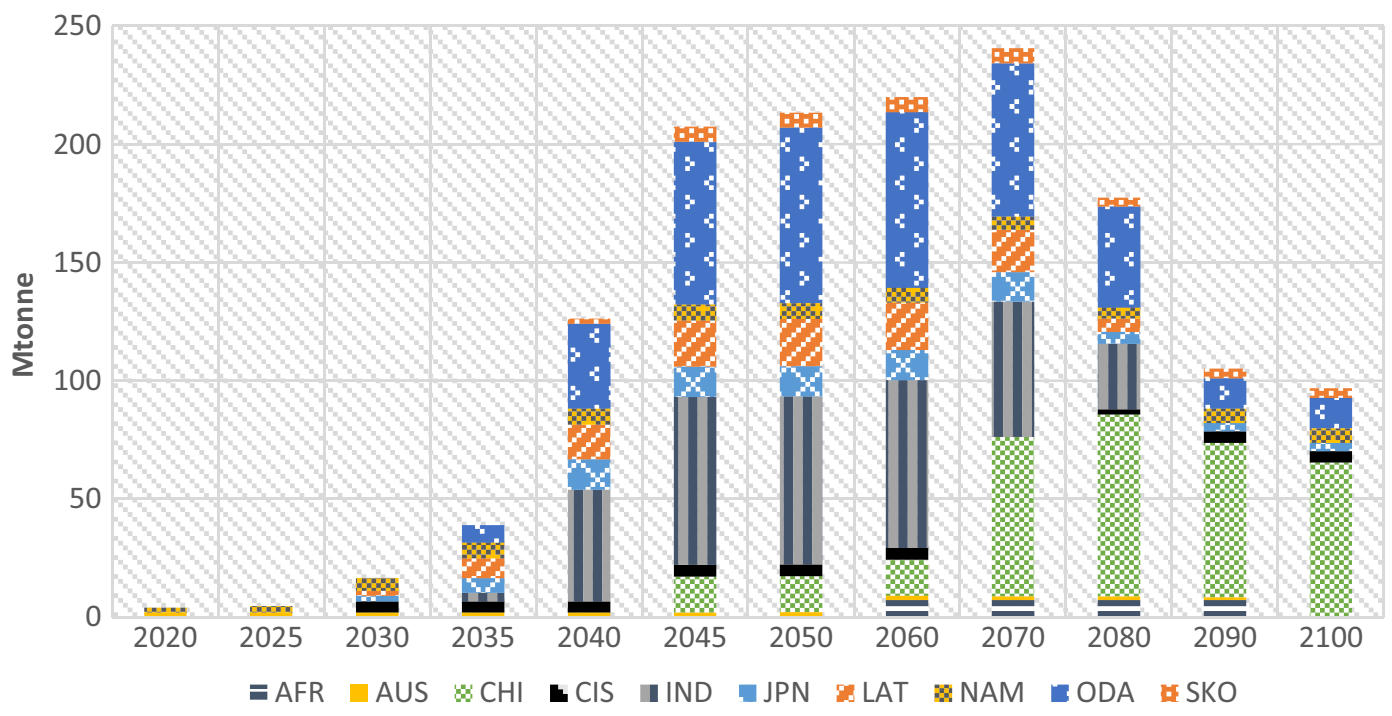

Fig. 19 Utilization of top gas recycling according to world regions (baseline scenario) 
Fig. 20 Worldwide utilization of top gas recycling under different scenario conditions

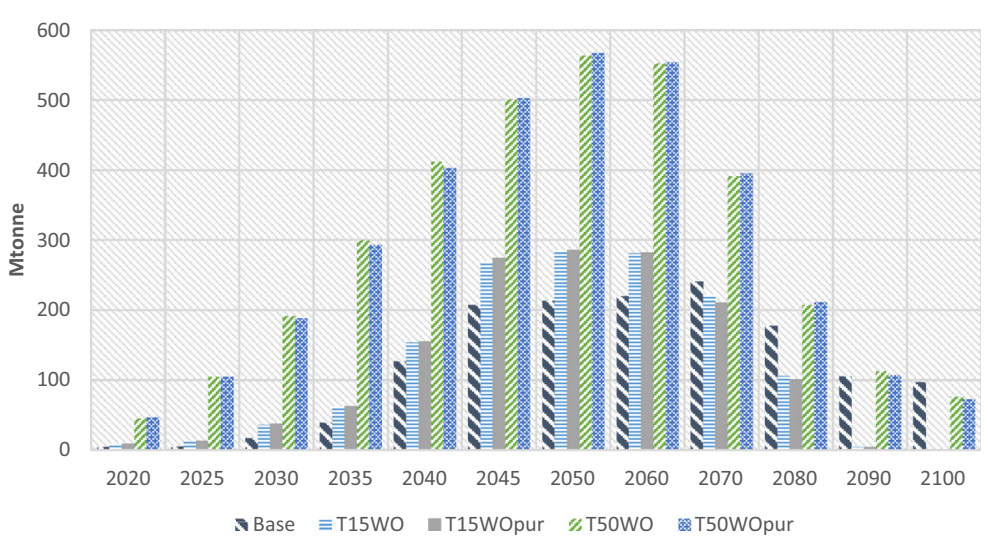

policies are introduced regionally - the results of the study show that high carbon costs (i.e., higher than 50 $€)$ may lead to a move of industries from the EU. On the other hand, uptaking of new technologies, such as scrap purification, might have similar effects on $\mathrm{CO}_{2}$ emissions as imposing a $50 €$ carbon price.

Globally, the use of steel scrap is estimated to grow from 611 Mtonnes in 2015 to 1500 Mtonnes in 2050, i.e., a $245 \%$ increase. The highest growth rate can be observed for the LQ scrap category. The increasing scrap availability justifies the projected deployment of EAF in the future. The large amount of LQ scrap available to the market triggers an increasing trade activity in the world. In 2050, close to half of the LQ scrap used globally will be traded among world regions. The majority of low-quality scrap is imported to countries projected to have high economic development until 2050, namely India and countries in Africa and Asia.

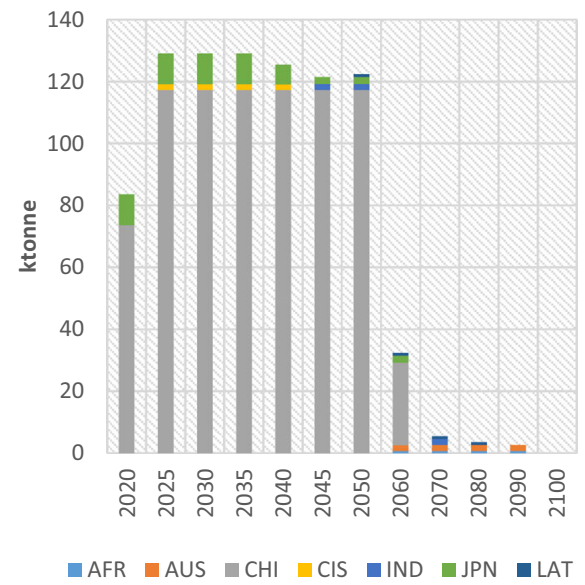

Fig. 21 Regional utilization of JET BOF technology in the T15WO scenario
Interestingly, secondary production routes will be favored regardless of policy instruments due to their lower costs and higher energy efficiency. That does not mean that primary production routes will cease to exist, as under the current assumptions in the model, the production of flat steel products predominantly appears to happen in blast oxygen furnace (BOF). EAF will be particularly important in the context of developing countries, where the demand for long steel products will be high due to increased infrastructure and construction needs.

Such a development illustrates the different dynamics at regional level: more scrap will become available in the developed regions of the world, but the demand for it exists in the developing regions. This poses a challenge on how future policies aiming for carbon emission reduction will address the issue of interregional trading of steel and scrap and how can indirect trade of steel and its

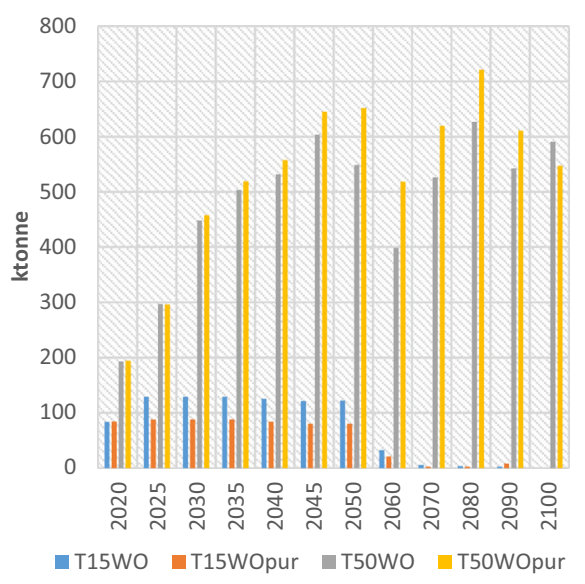

Fig. 22 Global uptake of JET BOF in different scenarios 
Fig. 23 Scrap purification uptake in EU 30 in selected scenarios

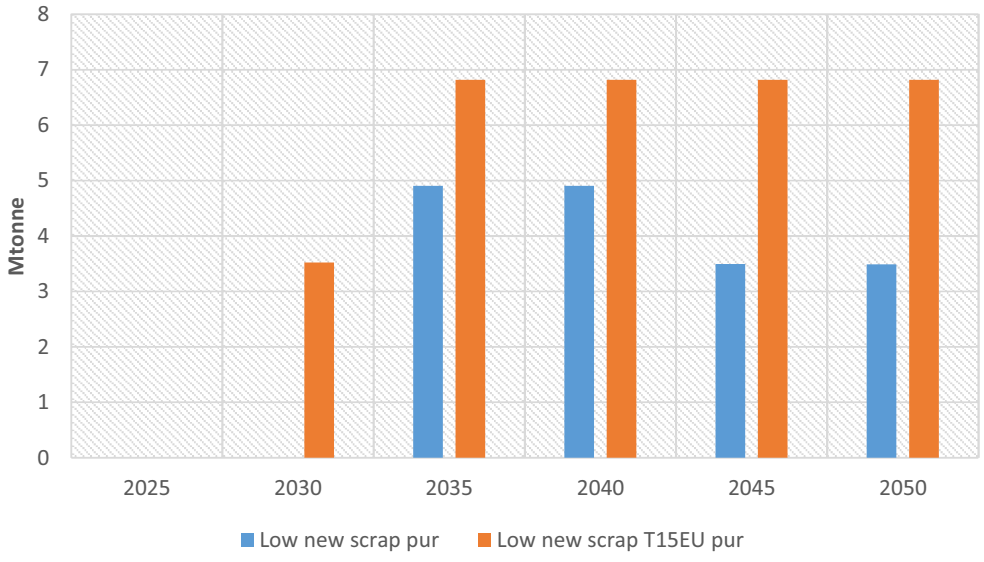

impacts be tracked in a highly connected world. Quantifying embodied emissions from interregional steel product trade becomes consequently a priority. Additionally, the contrast between regional scrap availability and demand will affect the pricing of the commodity and the transportation routes of it. Future decision on locating steel production plants will have to balance these two aspects; will it be more beneficial to locate the plants where there is demand or where the supply exists? This will greatly depend on the transportation costs. Additionally, more stringent carbon emission reduction policies, such as a global carbon tax, will lead to either co-locating steel demand and supply or choosing more environmentally friendly transportation routes and modes.

Finally, Introduction of emerging technologies, such as top gas recycling and JET BOF will be facilitated by the introduction of more stringent policy schemes. The development of scrap purification technologies might

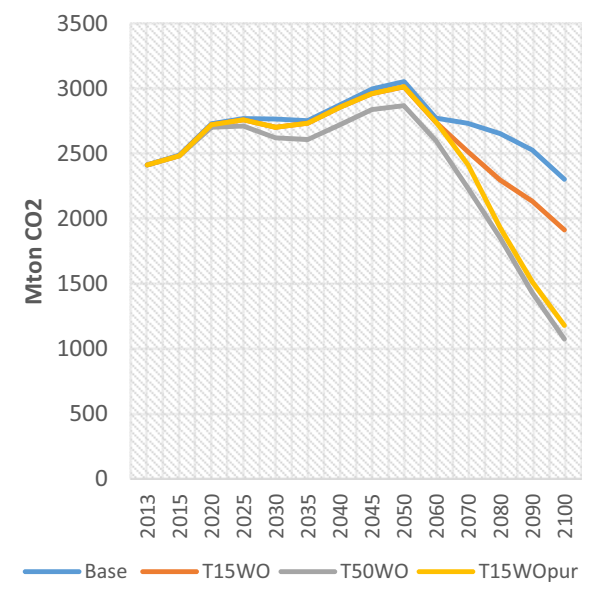

Fig. 24 Impact of $\mathrm{CO}_{2}$ price on global steel emissions become a priority in order to sustain the necessary LQ scrap flows for increased secondary steel production in the case of decreasing HQ scrap shares as material efficiency improves. Scrap purification would also be needed for avoiding steel contamination from copper and other tramp elements.

In the future, the models used in this study should include indirect steel trade in the simulations, as well as improved estimations for the ratio of long and flat steel products per steel product category, and evaluation of steel recycling rates at region-specific levels.

Acknowledgements A first version of the paper appeared in the proceedings of the eceee Industrial Efficiency 2016 conference, which took place 12-14 September at Berlin, Germany. The authors are grateful to Arcelor Mittal for partial funding of the study and for active participation in the reference group that developed the scenarios and analysis. The authors are grateful to the anonymous reviewers of the paper for the insightful comments that helped us improve the paper.

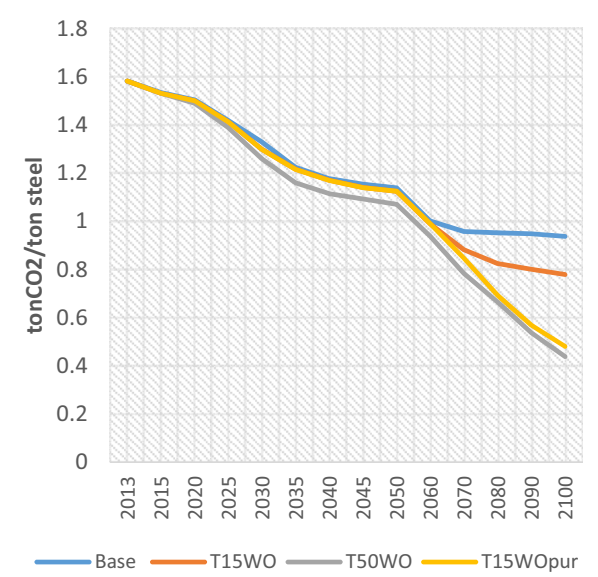

Fig. 25 Evolution of specific $\mathrm{CO}_{2}$ emissions in steel industry 
Fig. 26 Impact of a unilateral EU $\mathrm{CO}_{2}$ price on the EU flat steel production

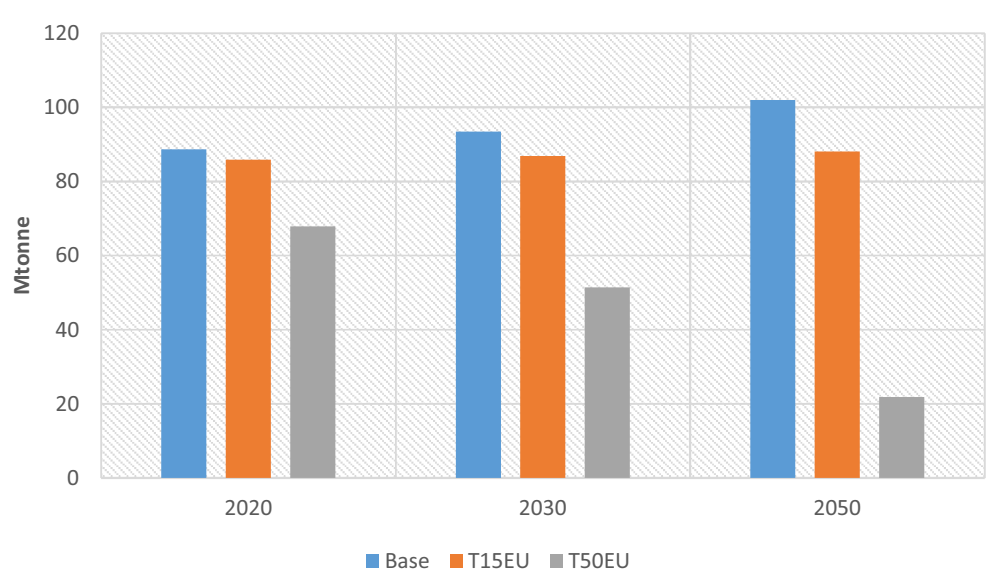

\section{Compliance with ethical standards}

Conflict of interest The authors declare that they have no con-

flict of interest.

\section{Appendix}

Table 7 List of world region acronyms used in the Steel Optimization Model and SAAM

\begin{tabular}{|c|c|c|c|c|c|}
\hline AFR & Africa & EU 30 & European Union & MEA & Middle East Asia \\
\hline AUS & Australia & IND & India & NAM & North America (incl. Central America) \\
\hline $\mathrm{CHI}$ & China & JPN & Japan & ODA & Other Developing Asia \\
\hline CIS & Ex-USSR, excl. EU 30 & LAT & Latin America & $\mathrm{OEU}$ & Other Europe \\
\hline
\end{tabular}

Table 8 List of abbreviations

\begin{tabular}{llll}
\hline ASU & Apparent steel use & FIXOM & Fixed operation and maintenance cost \\
BIR & Bureau of International Recycling & HQ scrap & High-quality scrap (new or pre-consumer scrap) \\
BOF & Blast oxygen furnace & LQ scrap & Low-quality scrap (old or post-consumer scrap) \\
DRI & Direct reduction iron & Mtonne & Megatonne (10^6tonne) \\
EAF & Electric arc furnace & SAAM & Scrap Availability Assessment Model \\
ETS & Emission trading scheme & VAROM & Variable operation and maintenance cost \\
\hline
\end{tabular}


Table 9 BOF production route characteristics

\begin{tabular}{|c|c|c|c|c|c|c|c|c|c|}
\hline Process & Commodity & $\begin{array}{l}\text { Fuel input } \\
\text { level }\end{array}$ & Unit & $\begin{array}{l}\text { Availability } \\
\text { factor }\end{array}$ & $\begin{array}{l}\text { Lifetime of } \\
\text { process }\end{array}$ & CAPEX & Unit & $\begin{array}{l}\text { Fixed } \\
\text { OPEX }\end{array}$ & $\begin{array}{l}\text { Var } \\
\text { OPEX }\end{array}$ \\
\hline \multicolumn{10}{|c|}{ BOF route long steel production } \\
\hline \multirow[t]{5}{*}{ Finishing steel BOF } & Casted steel & -1.07 & ton & 0.86 & 40 & 85 & EUR/tonne year & & 5.1 \\
\hline & High cal gas & -0.8 & GJ & & & & & & \\
\hline & Electricity & -0.2 & GJ & & & & & & \\
\hline & Finished steel & 1 & ton & & & & & & \\
\hline & Own scrap & 0.07 & ton & & & & & & \\
\hline \multirow[t]{2}{*}{ Casting steel- $\mathrm{BOF}$} & Steel & -1 & ton & 0.86 & 40 & 80 & EUR/ton year & & 0.1 \\
\hline & Casted steel & 1 & ton & & & & & & \\
\hline \multirow[t]{8}{*}{ Basic oxygen furnace } & Pig iron & -0.9 & ton & & 40 & 113 & EUR/ton year & 5 & 56 \\
\hline & Scrap & -0.18 & ton & & & & & & \\
\hline & Oxygen & -0.05 & ton & & & & & & \\
\hline & Lime & -0.05 & ton & & & & & & \\
\hline & Electricity & -0.1 & GJ & & & & & & \\
\hline & Steel & 1 & ton & & & & & & \\
\hline & BOF gas & 0.65 & GJ & & & & & & \\
\hline & BOF slack & 0.1 & ton & & & & & & \\
\hline \multirow[t]{9}{*}{ Blast furnace } & Sinter & -1505 & ton & 0.86 & 40 & 273 & EUR/ton year & 10 & 2 \\
\hline & Oxygen & -0.05 & ton & & & & & & \\
\hline & Coke & -9.3 & GJ & & & & & & \\
\hline & Cooking coal & $-6 / 2$ & GJ & & & & & & \\
\hline & Low cal gas & -2.1 & GJ & & & & & & \\
\hline & Electricity & -0.5 & GJ & & & & & & \\
\hline & Pig iron & 1 & ton & & & & & & \\
\hline & Blast furnace gas & 3.25 & GJ & & & & & & \\
\hline & Blast furnace slack & 0.25 & ton & & & & & & \\
\hline \multirow[t]{4}{*}{ Sinter production } & Iron ore & -1 & ton & 0.86 & 40 & 56 & EUR/ton year & 3 & 6 \\
\hline & Coke & -1.16 & GJ & & & & & & \\
\hline & Electricity & -0.1 & GJ & & & & & & \\
\hline & Sinter & 1 & ton & & & & & & \\
\hline \multirow[t]{4}{*}{ Coke production } & Cooking coal & -1.34 & GJ & 0.86 & 50 & 399 & EUR/Kw & & \\
\hline & Electricity & -0.056 & GJ & & & & & & \\
\hline & Coke & 1 & GJ & & & & & & \\
\hline & Coke gas & 0.174 & GJ & & & & & & \\
\hline \multirow[t]{2}{*}{ Oxygen production } & Electricity & -0.72 & GJ & 0.86 & 30 & 200 & EUR/ton year & 10 & \\
\hline & Oxygen & 1 & ton & 1 & & & & & \\
\hline
\end{tabular}


Table 10 EAF and DRI production routes

\begin{tabular}{|c|c|c|c|c|c|c|c|c|c|}
\hline Process & Commodity & $\begin{array}{l}\text { Fuel input } \\
\text { level }\end{array}$ & Unit & $\begin{array}{l}\text { Availability } \\
\text { factor }\end{array}$ & $\begin{array}{l}\text { Lifetime of } \\
\text { process }\end{array}$ & CAPEX & Unit & $\begin{array}{l}\text { Fixed } \\
\text { OPEX }\end{array}$ & $\begin{array}{l}\text { Var } \\
\text { OPEX }\end{array}$ \\
\hline \multicolumn{10}{|c|}{ EAF Route steel production } \\
\hline \multirow[t]{5}{*}{ Finishing steel EFA } & Casted steel & -1.07 & ton & 0.86 & 40 & 85 & EUR/ton year & & 5.1 \\
\hline & natural gas & -0.8 & GJ & & & & & & \\
\hline & Electricity & -0.2 & GJ & & & & & & \\
\hline & Finished steel & 1 & ton & & & & & & \\
\hline & Own scrap & 0.07 & ton & & & & & & \\
\hline \multirow{2}{*}{$\begin{array}{l}\text { Casting } \\
\text { long_-EFA }\end{array}$} & Steel & -1 & ton & 0.86 & 40 & 80 & EUR/ton year & & 0.1 \\
\hline & Casted steel & 1 & ton & & & & & & \\
\hline \multirow[t]{5}{*}{ Electric arc furnace } & Scrap & -1.05 & ton & 0.86 & 40 & 169 & EUR/ton year & 21 & 14 \\
\hline & Natural gas & -2.5 & GJ & & & & & & \\
\hline & Oxygen & -0.05 & ton & & & & & & \\
\hline & Electricity & -3 & GJ & & & & & & \\
\hline & Steel & 1 & GJ & & & & & & \\
\hline \multicolumn{10}{|c|}{ DRI - general DRI is assumed to be easily transportable and can be used for flat and long } \\
\hline \multirow[t]{4}{*}{ DRI general } & Pellets & -1.5 & ton & 0.86 & 40 & 230 & EUR/ton year & 2.25 & 1.35 \\
\hline & Electricity & -0.7 & GJ & & & & & & \\
\hline & Natural gas & -11 & GJ & & & & & & \\
\hline & DRI & 1 & ton & & & & & & \\
\hline \multirow[t]{4}{*}{ Pellet production } & Iron ore & -1 & ton & 0.86 & 40 & 62 & EUR/ton year & 3 & 5 \\
\hline & Electricity & -1.14 & GJ & & & & & & \\
\hline & Cokes & -1.01 & GJ & & & & & & \\
\hline & Pellets & 1 & ton & & & & & & \\
\hline
\end{tabular}

Table 11 By-products' valorization

\begin{tabular}{|c|c|c|c|c|c|c|c|c|c|}
\hline Process & Commodity & $\begin{array}{l}\text { Fuel input } \\
\text { level }\end{array}$ & Unit & $\begin{array}{l}\text { Availability } \\
\text { factor }\end{array}$ & $\begin{array}{l}\text { Lifetime } \\
\text { of } \\
\text { process }\end{array}$ & CAPEX & Unit & $\begin{array}{l}\text { Fixed } \\
\text { OPEX }\end{array}$ & $\begin{array}{l}\text { Var } \\
\text { OPEX }\end{array}$ \\
\hline \multicolumn{10}{|l|}{ By-products' valorisation } \\
\hline \multirow[t]{4}{*}{ Clinker production } & Limestone & -1.57 & ton & 0.86 & 40 & 270 & $\begin{array}{c}\text { EUR/ton } \\
\text { year }\end{array}$ & & \\
\hline & Coal & -3.4 & GJ & & & & & & \\
\hline & Electricity & -0.11 & GJ & & & & & & \\
\hline & Clinker & 1 & ton & & & & & & \\
\hline \multirow[t]{2}{*}{ Blast furnace gas plant } & Low cal gas & -2.6 & GJ & 0.86 & 30 & 1200 & $\mathrm{EUR} / \mathrm{kW}$ & & \\
\hline & Electricity & 1 & GJ & & & & & & \\
\hline \multirow[t]{2}{*}{ Coal plant } & Coal & -2.5 & GJ & 0.86 & 30 & 2000 & EUR/kW & & \\
\hline & Electricity & 1 & GJ & & & & & & \\
\hline \multirow[t]{2}{*}{ Natural gas plant } & Natural gas & -2 & GJ & 0.86 & 30 & 960 & $\mathrm{EUR} / \mathrm{kW}$ & & \\
\hline & Electricity & 1 & GJ & & & & & & \\
\hline
\end{tabular}


Table 12 Emerging technologies available from 2020 onwards

\begin{tabular}{|c|c|c|c|c|c|c|c|c|c|}
\hline Process & Commodity & $\begin{array}{l}\text { Fuel input } \\
\text { level }\end{array}$ & Unit & $\begin{array}{l}\text { Availability } \\
\text { factor }\end{array}$ & $\begin{array}{l}\text { Lifetime of } \\
\text { process }\end{array}$ & CAPEX & Unit & $\begin{array}{l}\text { Fixed } \\
\text { OPEX }\end{array}$ & $\begin{array}{l}\text { Var } \\
\text { OPEX }\end{array}$ \\
\hline \multirow[t]{7}{*}{ JET BOF } & Pig iron & -0.6 & ton & 0.86 & 40 & 133 & $\begin{array}{c}\text { EUR/ton } \\
\text { year }\end{array}$ & 5 & 66 \\
\hline & Scrap & -0.5 & ton & & & & & & \\
\hline & Oxygen & -0.03 & ton & & & & & & \\
\hline & Lime & -0.05 & ton & & & & & & \\
\hline & Electricity & -0.1 & GJ & & & & & & \\
\hline & Crude steel & 1 & ton & & & & & & \\
\hline & BOF slack & 0.1 & ton & & & & & & \\
\hline \multirow[t]{9}{*}{ Top gas recycled blast furnace } & Sinter & -1505 & ton & 0.86 & 40 & 387 & $\begin{array}{c}\text { EUR/ton } \\
\text { year }\end{array}$ & 12.5 & 3.5 \\
\hline & Oxygen & -0.05 & ton & & & & & & \\
\hline & Coke & -5.9 & GJ & & & & & & \\
\hline & Cooking coal & -5.2 & GJ & & & & & & \\
\hline & Low cal gas & -2.1 & GJ & & & & & & \\
\hline & Electricity & -0.2 & GJ & & & & & & \\
\hline & Pig Iron & 1 & ton & & & & & & \\
\hline & Blast furnace gas & 0.7 & GJ & & & & & & \\
\hline & Blast furnace slack & 0.25 & ton & & & & & & \\
\hline \multirow[t]{2}{*}{ Scrap purification } & Low-quality scrap & -1.1 & ton & & & 200 & $\begin{array}{c}\text { EUR/ton } \\
\text { year }\end{array}$ & 10 & 30 \\
\hline & High-quality scrap & 1 & ton & & & & & & \\
\hline
\end{tabular}

Open Access This article is distributed under the terms of the Creative Commons Attribution 4.0 International License (http:// creativecommons.org/licenses/by/4.0/), which permits unrestricted use, distribution, and reproduction in any medium, provided you give appropriate credit to the original author(s) and the source, provide a link to the Creative Commons license, and indicate if changes were made.

\section{References}

Arens, M., Worrell, E., Eichhammer, W. (2016). Drivers and barriers to the diffusion of energy-efficient technologies - a plant-level analysis of the German steel industry. Energy Efficiency, 1-17. https://doi.org/10.1007/s12053-016-9465-4.

Bureau of International Recycling. (2012). BIR Global facts and figures: world steel recycling in figures 2008-2012.

Daehn, K. E., Cabrera Serrenho, A., \& Allwood, J. M. (2017). How will copper contamination constrain future global steel recycling? Environmental Science \& Technology, 51(11), 6599-6606. https://doi.org/10.1021/acs.est.7b00997.
Engle, R. F., \& Granger, C. W. J. (1987). Co-integration and error correction: representation, estimation, and testing. Econometrica, 55(2), 251. https://doi.org/10.2307/1913236.

EUROFER. (2016). Steel recycling [WWW Document]. URL http://www.eurofer.org/SustainableSteel/SteelRecycling. fhtml. Accessed 4.18.16.

Graedel, T. E., Allwood, J., Birat, J.-P., Reck, B. K., Sibley, S. F., Sonnemann, G., Buchert, M., Hagelüken, C. (2011a). Recycling rates of metals - a status report, A Report of the Working Group on the Global Metal Flows to the International Resource Panel.

Graedel, T. E., Allwood, J., Birat, J. P., Buchert, M., Hagelüken, C., Reck, B. K., Sibley, S. F., \& Sonnemann, G. (2011b). What do we know about metal recycling rates? Journal of Industrial Ecology, 15(3), 355-366. https://doi.org/10.1111 j.1530-9290.2011.00342.x.

Grosse, F. (2010). Is recycling "part of the solution"? The role of recycling in an expanding society and a world of finite resources. Surveys and Perspective Integrating Environment \& Society, 3, 1-30.

Institute of Scrap Recycling Industries. (2012). The ISRI scrap yearbook 2012. Washington DC, USA. 
Johansson, M. T. (2015). Improved energy efficiency within the Swedish steel industry - the importance of energy management and networking. Energy Efficiency, 8(4), 713-744. https://doi.org/10.1007/s12053-014-9317-z.

Kuramochi, T. (2015). Assessment of midterm CO2 emissions reduction potential in the iron and steel industry: a case of Japan. Journal of Cleaner Production, 17. https://doi. org/10.1016/j.jclepro.2015.02.055.

Loulou, R., \& Labriet, M. (2008). ETSAP-TIAM: the TIMES integrated assessment model Part I: model structure. Computational Management Science, 5(1-2), 7-40. https://doi.org/10.1007/s10287-007-0046-Z.

Morfeldt, J., \& Silveira, S. (2014). Capturing energy efficiency in European iron and steel production - comparing specific energy consumption and Malmquist productivity index. Energy Efficiency, 7(6), 955-972. https://doi.org/10.1007/s12053014-9264-8.

Morfeldt, J., Silveira, S., Nijs, W. (2012). Shaping our energy system-combining European modelling expertise Case study. Stockholm.

Morfeldt, J., Nijs, W., \& Silveira, S. (2015). The impact of climate targets on future steel production - an analysis based on a global energy system model. Journal of Cleaner Production, 103, 469-482. https://doi.org/10.1016 /j.jclepro.2014.04.045.

Oda, J., Akimoto, K., \& Tomoda, T. (2013). Long-term global availability of steel scrap. Resources, Conservation and Recycling, 81, 81-91. https://doi.org/10.1016/j. resconrec.2013.10.002.

Pauliuk, S., Milford, R. L., Müller, D. B., \& Allwood, J. M. (2013a). The steel scrap age. Environmental Science \& Technology, 47(7), 3448-3454. https://doi.org/10.1021 les303149z.

Pauliuk, S., Wang, T., \& Müller, D. B. (2013b). Steel all over the world: estimating in-use stocks of iron for 200 countries. Resources, Conservation and Recycling, 71, 22-30. https://doi.org/10.1016/j.resconrec.2012.11.008.

Serrenho, A. C., Mourão, Z. S., Norman, J., Cullen, J. M., \& Allwood, J. M. (2016). The influence of UK emissions reduction targets on the emissions of the global steel industry. Resources, Conservation and Recycling, 107, 174-184. https://doi.org/10.1016/j.resconrec.2016.01.001.

Söderholm, P., \& Ejdemo, T. (2008). Steel scrap markets in Europe and the USA. Minerals \& Energy, 23(2), 57-73. https://doi. org/10.1080/14041040802018497.
The Boston Consulting Group \& Steel Institute VDEh. (2013). Steel's contribution to a low-carbon Europe 2050. Boston: The Boston Consulting Group, Inc.

United Nations. (2015a). World Population Prospects: The 2015 Revision, DVD Edition. [WWW Document]. Dep. Econ. Soc. Aff. Popul. Div. URL http://esa.un. org/unpd/wpp/DVD/.

United Nations. (2015b). UN Comtrade Database [WWW Document]. URL http://comtrade.un.org/. Accessed 2.16.15.

Wang, T., Muller, D. B., \& Graedel, T. E. (2007). Forging the anthropogennic iron cycle. Environmental Science \& Technology, 41(14), 5120-5129. https://doi.org/10.1021 les062761t.

Wang, P., Jiang, Z., Geng, X., Hao, S., \& Zhang, X. (2014). Quantification of Chinese steel cycle flow: historical status and future options. Resources, Conservation and Recycling, 87, 191-199. https://doi.org/10.1016/j. resconrec.2014.04.003.

Wang, P., Li, W., \& Kara, S. (2015). Cradle-to-cradle modeling of the future steel flow in China. Resources, Conservation and Recycling, 117, 45-57. https://doi.org/10.1016/j. resconrec.2015.07.009.

World Steel Association. (2012a). World steel in figures 2012. Brussels, Belgium.

World Steel Association. (2012b). Indirect trade in steel. Brussels, Belgium.

World Steel Association. (2013). World steel association-yearbook archive [WWW Document]. URL http://www. worldsteel.org/statistics/statistics-archive/yearbook-archive. html.

Wubbeke, J., \& Heroth, T. (2014). Challenges and political solutions for steel recycling in China. Resources, Conservation and Recycling, 87, 1-7. https://doi.org/10.1016/j. resconrec.2014.03.004.

Xuan, Y., \& Yue, Q. (2016). Forecast of steel demand and the availability of depreciated steel scrap in China. Resources, Conservation and Recycling, 109, 1-12. https://doi. org/10.1016/j.resconrec.2016.02.003.

Xylia, M., Kuder, R., Blesl, M., Brunke, J.-C., \& Silveira, S. (2014). Low-CO2 steel production: European perspective on the steel market and the role of scrap. Karsruhe: ESA2Energy Systems Analysis Agency.

Yellishetty, M., Mudd, G. M., \& Ranjith, P. G. (2011). The steel industry, abiotic resource depletion and life cycle assessment: a real or perceived issue? Journal of Cleaner Production, 19(1), 78-90. https://doi.org/10.1016/j.jclepro.2010.08.020. 